\title{
Fine wine or sour grapes? A systematic review and meta-analysis of the impact of red wine polyphenols on vascular health
}

\author{
Samuel R. Weaver ${ }^{1}$ (D) $\cdot$ Catarina Rendeiro ${ }^{1,2} \cdot$ Helen M. McGettrick $^{3} \cdot$ Andrew Philp $^{1,4,5} \cdot$ Samuel J. E. Lucas ${ }^{1,2}$
}

Received: 12 November 2019 / Accepted: 1 April 2020 / Published online: 17 April 2020

(c) The Author(s) 2020

\begin{abstract}
Purpose Red wine polyphenols (RWP) are plant-based molecules that have been extensively studied in relation to their protective effects on vascular health in both animals and humans. The aim of this review was to quantify and compare the efficacy of RWP and pure resveratrol on outcomes measures of vascular health and function in both animals and humans. Methods Comprehensive database searches were carried out through PubMed, Web of Science and OVID for randomised, placebo-controlled studies in both animals and humans. Meta-analyses were carried out on acute and chronic studies of RWP in humans, alongside sub-group analysis where possible. Risk-of-bias assessment was carried out for all included studies based on randomisation, allocation, blinding, outcome data reporting, and other biases.

Results 48 animal and 37 human studies were included in data extraction following screening. Significant improvements in measures of blood pressure and vascular function following RWP were seen in $84 \%$ and $100 \%$ of animal studies, respectively. Human studies indicated significant improvements in systolic blood pressure overall (-2.6 mmHg, 95\% CI: $[-4.8,-0.4])$, with a greater improvement in pure-resveratrol studies alone $(-3.7 \mathrm{mmHg}, 95 \% \mathrm{CI}$ : $[-7.3,-0.0])$. No significant effects of RWP were seen in diastolic blood pressure or flow-mediated dilation (FMD) of the brachial artery.

Conclusion RWP have the potential to improve vascular health in at risk human populations, particularly in regard to lowering systolic blood pressure; however, such benefits are not as prevalent as those observed in animal models.
\end{abstract}

Keywords Red wine $\cdot$ Polyphenols $\cdot$ Resveratrol $\cdot$ Vascular health $\cdot$ Blood pressure

\section{Introduction}

Red wine polyphenols (RWP) first came to prominence within the field of nutrition in the 1980's with the identification of the "French Paradox" [1]. This theory pointed to the

Samuel R. Weaver

SRW199@bham.ac.uk

1 School of Sport, Exercise and Rehabilitation Sciences, College of Life and Environmental Sciences, University of Birmingham, Birmingham B15 2TT, UK

2 Centre for Human Brain Health, University of Birmingham, Birmingham B15 2TT, UK

3 Institute of Inflammation and Ageing, College of Medical and Dental Sciences, University of Birmingham, Birmingham B15 2WB, UK

4 Garvan Institute of Medical Research, Darlinghurst, NSW 2010, Australia

5 St Vincent's Clinical School, UNSW Medicine, UNSW Sydney, Sydney, NSW 2010, Australia high levels of red wine consumed by the French as one factor that may explain the relatively low level of coronary heart disease (CHD) within the country, despite their high fat dietary habits [1]. Following on from these initial findings, accumulating evidence in the last 30 years suggests that specific polyphenol components within RWP can exert protective actions within the vascular system in both humans and animal models [2, 3]. In rodents, chronic supplementation with RWP and isolated RWP components has been shown to lead to improvements in both blood pressure and vascular responsiveness in excised vessels across a wide range of disease models, such as diabetes, obesity, hypertension and aging [4-10]. In vitro studies using human endothelial cells [11-13] also demonstrated reduced NADPH oxidase activity, reduced inflammation and increases in endothelial nitric oxide production via increases in endothelial nitric oxide synthase (eNOS) activity and intracellular $\mathrm{Ca}^{2+}$ concentration in response to RWP pre-treatment. Acute and chronic human randomized controlled trials have also revealed benefits of RWP supplementation within the vasculature, 
particularly, improvement in blood pressure and endothelial function $[14,15]$. However, human intervention studies with RWP generally report less consistent findings across different populations (e.g., young, aged, obese, hypertensive, type II diabetic) and specific RWP [16-19], in comparison to preclinical animal models.

RWP comprise a complex and varied array of molecules, including flavonoids such as (+)-catechin, quercetin, anthocyanins, and the stilbene families of polyphenols [resveratrol (3, 5, 4'-trihydroxystilbene)] [2]. These have been isolated and studied with the objective of identifying the key polyphenolic components driving the beneficial effects on vascular health [2]. Evidence in vivo and under physiological relevant conditions in vitro, has shown that many of these compounds can have a wide range of physiological effects within the vasculature by activating key signal pathways such as insulin receptor 1 (IR-1) and sirtuin 1 (SIRT1), which are involved in insulin sensitivity, inflammation and cellular regulation [20]. Amongst RWP, resveratrol has emerged as a key component in regulating vascular homeostasis, and has been shown to interact with both IR-1 and SIRT1 when applied to either endothelial cells in culture and excised aortic arterial tissue ex vivo [21]. Modulation of these pathways has the potential to result in an increase in antioxidant capacity; improved metabolic health; and can act to regulate endothelial function through activation and upregulation of eNOS while inhibiting inflammatory pathways [21, 22]. Studies in rodents have shown that greater Nitric Oxide (NO) availability, reduced inflammation and improved antioxidant capacity can all contribute to improve vascular function through increased vasodilatory capacity, vessel compliance and reduced blood pressure [3, 23-25]. Indeed, animal studies in healthy subjects or disease models of hypertension, type II diabetes and metabolic syndrome, have shown improvements in blood pressure and vascular function following chronic supplementation with both whole extract polyphenols and pure compounds including resveratrol, quercetin and pterostilbene [6-8, 24, 26]. In contrast, in healthy human populations there is a consistent lack of efficacy on vascular outcomes [27, 28], but greater variability in the beneficial responses within clinical populations, including type II diabetes, obesity and hypertension [17, 19, 29-31].

There are a number of important aspects that must be considered when directly comparing polyphenol interventions in animal and humans. Firstly, the metabolic fate of dietary polyphenols is highly varied both within and between species: it can be dose-dependent, and be influenced by the background diet and composition of gut microbiota [32-35]. Further differences in metabolic rate between humans and animals demands that careful consideration is given to ensure that equivalent dietary relevant doses are administered across species [36]. Finally, animal studies benefit from highly controlled environments which include controlled background diets that are typically polyphenolfree. In humans this level of control is not possible, and in cases, where dietary restrictions are put into place adherence to restrictions, guidelines, and interventions themselves can vary greatly $[37,38]$.

Previous systematic reviews have mainly focussed on the effects of pure RWP in at-risk populations, with arterial blood pressure as the key outcome measure [14, 39, 40]. Limited attention has so far been given to effects of whole RWP, which are expected to be more relevant within the context of normal diets. Furthermore, the impact of these polyphenolic compounds on key predictive outcome measures of future cardiovascular risk, such as brachial flow mediated dilation (FMD)) as well as cerebral vascular function is limited. Finally, to the best of our knowledge, no review has assessed the consensus within animal model studies and directly compared these to the effects reported in humans. This systematic review, therefore, aims to quantify and compare the effects of whole RWP and pure resveratrol on whole body vascular health and function (blood pressure, flow-mediated dilation and $\mathrm{CO}_{2}$ reactivity in the cerebrovasculature) in both animal and human models. In addition, we aim to determine the impact of different human populations (e.g., health status, age and BMI) and study characteristics (e.g., type, dose and duration of supplementation) on vascular outcome measures in response to RWP.

\section{Methods}

This review was carried out following the Preferred Reporting System for Systematic reviews and Meta-Analyses (PRISMA) guidelines. A full, updated version of the review protocol was produced following the PRISMA-P guide [41, 42] and published on the PROSPERO register (https://www. crd.york.ac.uk/prospero) under the registration number CRD42018103246, which including details on complete sample search query, inclusion and exclusion criteria, and data extraction and analysis.

\section{Search strategy}

Systematic database searches were carried out from July to November 2018, through MEDLINE (PubMed, 1948 onwards), EMBASE (Ovid, 1980 onwards) and the Web of Science Core Collection (Clarivate Analytics, 1900 onwards). Search terms were selected based on the well supported PICO format, which separates terms based on Population, Intervention, Comparison and Outcome [41, 43] and are detailed in Table 1. Population terms were included to search for both animal model and human studies, to collect studies within both population types for comparison of 
Table 1 Search terms used for database searches, based on the PICO System for search strategy development

\begin{tabular}{|c|c|c|c|}
\hline Patient/population/problem & Intervention & Comparison/Control & Outcome \\
\hline $\begin{array}{l}\text { Mice } \\
\text { Mouse } \\
\text { Rodent* } \\
\text { Animal } \\
\text { Animal model[MH] } \\
\text { OR } \\
\text { Healthy adult* } \\
\text { Young adult* } \\
\text { Adult* } \\
\text { Cardiovascular disease[MH] } \\
\text { CVD } \\
\text { TIIDM OR T2DM } \\
\text { Diabet* } \\
\text { Overweight } \\
\text { Obese } \\
\text { Elder* } \\
\text { Old* adj3 adult* } \\
\text { Aging }\end{array}$ & $\begin{array}{l}\text { Red wine polyphenol } \\
\text { RWP } \\
\text { Resveratrol } \\
\text { Pterostilbene[MH] } \\
\text { *stilbene }\end{array}$ & $\begin{array}{l}\text { Placebo } \\
\text { Control } \\
\text { Negative control } \\
\text { (Polyphenol adj3 free adj3 control) }\end{array}$ & $\begin{array}{l}\text { *Vascular function } \\
\text { *Vascular responsiveness } \\
\text { *Vascular reactivity } \\
\text { Blood pressure } \\
\text { (OR BP) } \\
\text { Transcranial doppler (TCD) } \\
\text { Flow mediated dilation (FMD) } \\
\text { fMRI } \\
\text { Blood flow } \\
\text { Peripheral blood flow } \\
\text { Cerebrovascular blood flow }\end{array}$ \\
\hline
\end{tabular}

the results of RWP supplementation in both, as previously stated. Full details of the search terms used alongside an example search for the Medline database can also be found on the PROSPERO register.

\section{Selection criteria and screening procedure}

Full citation results for all searches were collected and, following removal of duplicates, were screened for inclusion/exclusion using the Rayyan online screening tool [44]. Systematic reviews and meta-analyses found during literature searches were manually screened for additional studies that were not found in the results of initial database searches. Studies were initially screened by their abstracts and were included for full text screening and data extraction if: (1) a specific RWP supplement was orally administered, with doses stated and an appropriate placebo/control was administered; (2) outcome measures/methods included one or more measure of blood pressure; cerebral or peripheral vascular function, and (3) details of the specific population included health and disease status. This review aimed to determine the impact of extracted RWP and specific polyphenol isolates. Due to the differences in delivery, dosage and inter-variety/batch variability of whole wine/juice [45], all of which make direct comparison problematic, studies investigating the impact of unrefined grape juice or alcoholised/de-alcoholised red wine were excluded.

In relation to human-based studies, studies were included if the study design included appropriate randomisation, treatment blinding and either a placebo/control arm or a cross-over method was applied. In the case of animal-based studies, ex vivo analysis of vascular function in excised artery samples was also considered an acceptable outcome measure for inclusion.

Following initial screening, included studies were then assessed as full-texts to determine final inclusion/exclusion and were separated into human and animal study categories to ensure that full details were available regarding the supplement type and dosage; duration of supplementation; primary outcome measures; population demographics and clinical characteristics; and study design. Final exclusion produced a total of 89 studies for full data extraction; quality assessment and analysis; full details of the reasons for exclusion are shown in Table 2.

\section{Data extraction and quality assessment}

A single reviewer ( $\mathrm{SW}$ ) completed the searches, study selection, data extraction and quality assessment. A second reviewer assessed all full-text exclusion justifications and was consulted in cases, where inclusion/exclusion was uncertain (CR). In the event of a disagreement between reviewers one and two, a third reviewer independently assessed the matter and made a final decision regarding inclusion/exclusion (SL). These precautions were taken to minimise the risk of single reviewer selection error, as recommended in the Cochrane guidelines [46].

Data extracted included publication details (authors, date, journal, title, etc.); study design characteristics (randomisation, placebo/controls, etc.); population details (number, sex, age, physical characteristics, health/disease status and medication usage); the type of RWP used; the dosage and duration used for supplementation; and all data available on pre- vs. post-supplementation and control vs. supplementation vascular measures. If data were not available for 
Table 2 Study exclusion and summary of reason/justification of exclusion from the present review

\begin{tabular}{|c|c|c|}
\hline $\begin{array}{l}\text { Number } \\
\text { of stud- } \\
\text { ies }\end{array}$ & Study & Reason for Exclusion \\
\hline 6 & $\begin{array}{l}\text { Akaberi et al., 2016; Baile et al., 2011; Belcaro et al., 2013; } \\
\text { Evans et al., 2016; Karatzi et al., 2009; Wong et al., } 2013\end{array}$ & $\begin{array}{l}\text { Not RCT (review article or non-randomised/non-placebo control } \\
\text { study) }\end{array}$ \\
\hline 19 & $\begin{array}{l}\text { Always et al., 2017; Bashmakov et al., 2014; Baur et al., 2006; } \\
\text { Brasnyo et al., 2011; Care et al., 2016; Chan et al., 2008; Glie- } \\
\text { mann et al., 2013; Goh et al. 2014; Gordish et al., 2014; Robich } \\
\text { et al., 2010; Palmisciano et 1., 2015; Pollack et al., 2017; } \\
\text { Poulsen et al., 2013; Shahraki et al., 2017; Soner et al., 2014; } \\
\text { Thazhath et al., 2016;Tome-Carneiro et al., 2012a; 2012b; Zare } \\
\text { et al., } 2017\end{array}$ & $\begin{array}{l}\text { Primary outcomes for the review were not presented or not shown } \\
\text { in full (e.g., no pre-trial data, no placebo results, only presented } \\
\text { as figure) }\end{array}$ \\
\hline 17 & $\begin{array}{l}\text { Biesinger et al., 2016; Chan et al., 2008; Chu et al., 2011; Cruz, } \\
\text { 2006; Dorri et al., 2017; Gordish et al., 2014; Idris-Khodja } \\
\text { et al., 2013; Karatzi et al., 2004; Sarr et al., 2006; Silan et al., } \\
\text { 2008; Subramanian et al., 2011; Taguchi et al., 2014; 2015; } \\
\text { Toklu et al., 2010; Wang et al., 2002; Wang et al., 2005; Xu } \\
\text { et al., } 2009\end{array}$ & $\begin{array}{l}\text { Not oral administration of RWP or RSV (detail of supp not given/ } \\
\text { whole juice or wine/injection of supp/cell culture) }\end{array}$ \\
\hline 5 & $\begin{array}{l}\text { Bienholz et al., 2017; Chander et al., 2006; Lopez-Sepulveda } \\
\text { et al., 2008; Mozafari et al., 2016; Song et al., } 2005\end{array}$ & No isolation of RWP effects (surgery response) \\
\hline 3 & Botden et al., 2012; Wong et al., 2016; Xu et al., 2009 & Duplicates \\
\hline
\end{tabular}

primary outcome measures reported in methods sections, the authors were contacted by the correspondence email address and the date of contact was recorded. In the case of studies that included multiple doses of a single supplement or comparisons of multiple supplements, all included measures were extracted and recorded as separate trials.

The quality of studies was judged in accordance with the Cochrane Collaborations recommendations with bias being judged based on six criteria covering random sequence generation; allocation concealment (selection bias); blinding of participants and researchers (performance bias); blinding of outcome assessment (detection bias); incomplete outcome data (attrition bias) and selective reporting (reporting bias); as well as the reporting of sources of funding and conflicts of interest (additional bias source) [47]. These sources of bias were rated as either high risk, uncertain risk or low risk, and allocated a score of 1,0 or -1 , respectively, to give an overall rating of bias risk for each study. In accordance with well established guidelines regarding risk of bias assessment, these scores were not taken into account in determining the estimated effect size of each study, but were used to examine bias as a potential cause for heterogeneity within the results [43].

\section{Statistical analysis}

\section{Animal studies}

Animal studies were evaluated to determine the proportion of studies that saw a significant improvement in blood pressure or vascular function following RWP treatment, including sub-group analysis between healthy and at-risk/ disease-model populations. In addition, summary statistics were calculated to determine the range of supplements used and the average supplementation period, presented as mean and standard deviation or proportion of total studies included.

\section{Data extraction and synthesis}

In human studies, the primary outcome measures were overall change in vascular measures between pre- and post-intervention, calculated as the difference in mean values. Blood pressure results were extracted as systolic and diastolic blood pressure, either as seated "office" measurement using a portable brachial artery cuff, or as ambulatory blood pressure over a 12 - or 24 -h period with the mean being included in subsequent quantitative analysis. Vascular functional measures of brachial artery dilation in response to shear stress were extracted either as percentage or absolute diameter change, as well as shear rate if reported (which uses diameter change and blood flow velocity to give an indication of artery wall shear stress). Transcranial doppler measures were extracted as cerebral blood flow velocity through the middle cerebral artery (MCAv) and/or posterior cerebral artery (PCAv), with comparison being made between studies using matching target artery velocity measures only.

If measures were presented as mean difference with 95\% confidence intervals, the Cochrane Handbook method (7.7.7.2) for calculating standard difference from 95\% CI's was applied [48]. In the case of studies reporting non-parametric results in the form of median and interquartile range, 
the mean and standard deviation were estimated from the sample size, median and interquartile range [49]. Studies were separated based on whether the intervention was acute or chronic, and qualitative and quantitative analysis was carried out separately to differentiate the acute and chronic effects of supplementation. All data were calculated and presented as mean \pm SD unless otherwise explicitly stated.

\section{Quantitative analysis}

Mean differences between the start and end of the intervention period were calculated with comparison between group mean differences, and overall effect estimates were calculated by random effect models, and reported alongside estimate significance ( $p$ value) and heterogeneity $\left(I^{2}\right)$, with significance being determined based on a $p$ value below an alpha value of $\alpha=0.05$. All blood pressure data were reported with the same unit of measure across all studies, allowing mean differences to be used for models to estimate a weighted mean difference. Vascular function data [e.g., flow-mediate dilation (FMD) response] were reported as both percentage change and diameter change; therefore, standardised mean differences were calculated to estimate overall effect size. The $I^{2}$ statistic was examined to evaluate heterogeneity, with $I^{2}>50 \%$ and $I^{2}>75 \%$ indicative of substantial and considerable heterogeneity, respectively [50].

\section{Moderator and meta-regression analysis}

Subgroup analyses were carried out to identify possible sources of heterogeneity; specifically by comparison of overall and subgroup estimated effects based on the type of supplement used and the health status of the participant cohort. Meta-regression was assessed using mixed effect models to evaluate the impact that potential moderators had on the estimated effect and heterogeneity of overall and subgroup effects. Models were run collectively to reduce the likelihood of failure to detect a moderator due to suppression, or over complication of moderator influence due to undetected confounding interactions between moderators [51]; with the exception of medication status, which was run in isolation on the at-risk subgroup due to the potential for interaction effects. The impact of moderators on the effects of supplementation was evaluated by assessing the proportion of heterogeneity each one accounted for, with significance determined by an Omnibus test for the overall model effect and Wald-type Chi-Squared tests for each moderator within the model.

\section{Sensitivity analysis}

Externally standardised studentized deleted residuals were used to evaluate and identify potential outliers, based on the size of each study's individual residual, with residual values $<-2$ or $>2$ considered to be outlying. The impact of outliers on the overall result was then assessed using model fit impact analysis (DFFITS and Cook's distance); covariance from the mean; residual heterogeneity test statistics; overall result influence (hat values); and study weight [52]. If a study was found to be outlying and to have reasonable influence on the overall result, the random effect model was refitted and reported with and without influential outlying studies. All statistical analyses were performed in RStudio [53] using the Metafor meta-analysis package [54], and all effect estimates are reported as mean difference with 95\% confidence intervals (MD, [95\% CI]) unless otherwise stated.

\section{Search results}

The search, screening and selection process for eligible studies is shown in Fig. 1. A total of 759 studies were found through database searches and were included in preliminary screening, with an additional 31 studies found in reviews that had been identified as relevant through the original database searches. Of these studies, following removal of duplicates a total of 607 were screened by title and abstract, 466 of these were excluded due to either a lack of randomisation of placebo/control group, usage of a supplement that did not match the inclusion criteria; or absence of details on the required primary outcome measures. 141 full-text articles were then screened and divided into animal and human studies, of which 50 were excluded from data extraction due to: incorrect study design/non-randomised control trials (RCT) study $(n=6)$; primary outcomes not present $(n=19)$; nonoral RWP supplementation ( $n=17)$; RWP response not tested in isolation $(n=5)$; or data were a duplicate of an included study $(n=3)$.

\section{Results}

\section{Animal studies}

48 of the included studies were conducted in animal models, the majority of which were in rat models $(n=36)[4$, $9,55-87]$, alongside studies in mice $(n=9)$ [10, 88-95], rabbits $(n=2)[8,96]$ and swine $(n=1)$ [7]. Of these all, but three, investigated the effects of RWP in clinical or disease models, including induced hypertension $(n=8)$, diabetes $(n=4)$, ageing $(n=6)$ and high fructose-induced vascular dysfunction $(n=7)$, with 25 studies including a healthy supplemented population (Table 3). A range of different RWP were used, including red wine extract, grape seed extract and whole-grape RWP, although the majority used single polyphenol supplementation with resveratrol (full details shown 


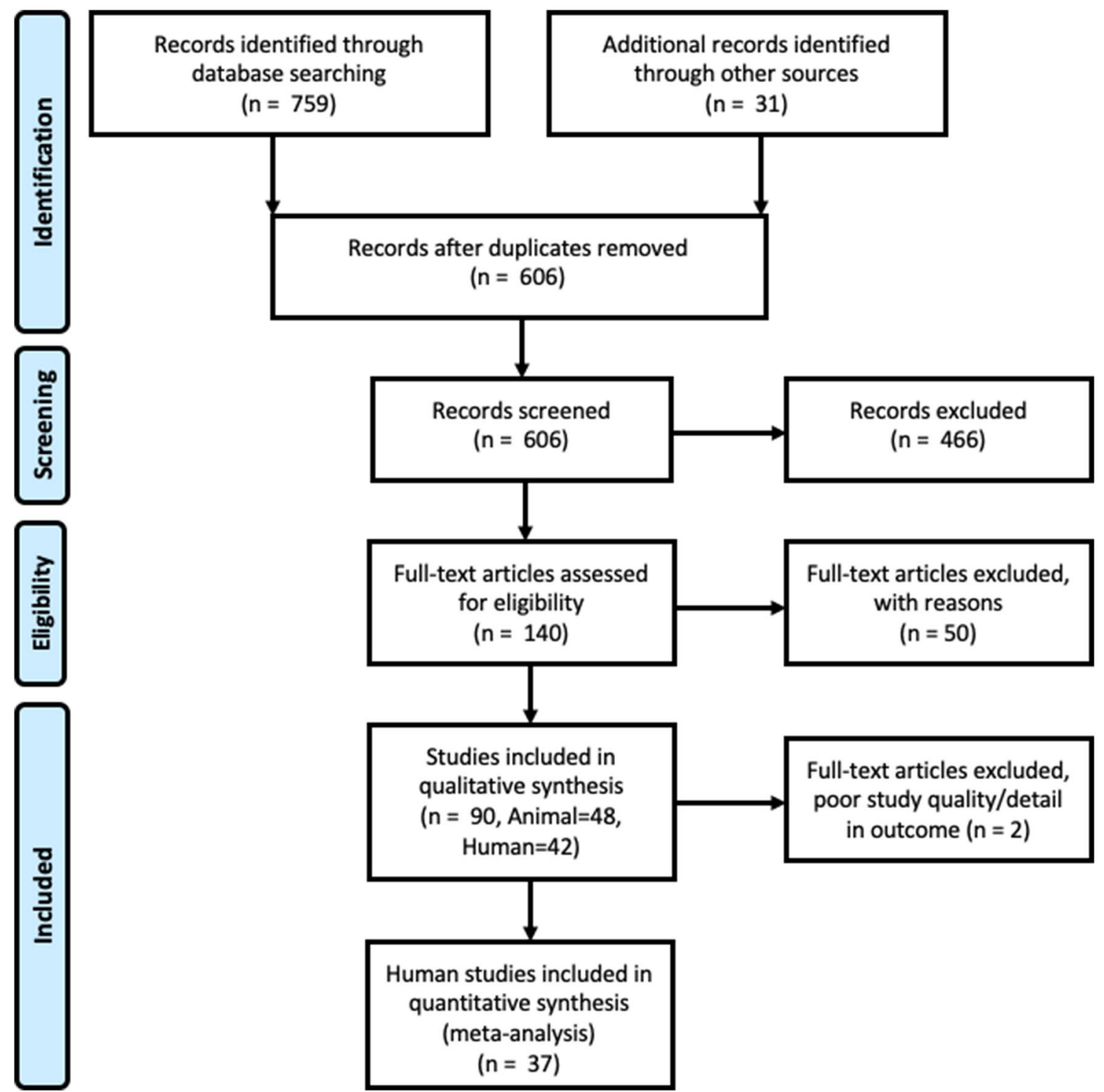

Fig. 1 PRISMA flow diagram showing the search, screening and selection process, including eligible study numbers for both qualitative and quantitative synthesis

in Table 3). None of the studies investigated acute supplement effects alone, with the average duration of treatment being $8.5 \pm 6.9$ weeks. Significant improvements in vascular measures were seen after supplementation in $24 \%$ of studies in healthy animals, with specific significant effects on blood pressure $(n=21)$ and vascular function in arterial rings ex vivo $(n=10)$ in $24 \%$ and $40 \%$ of studies, respectively. Compared to response in healthy animals, studies in disease/clinical animal models saw significant improvements in the majority (88\%) of studies, with $84 \%$ and $100 \%$ in blood pressure (BP) and vascular function measures, respectively.

Average intervention dosages can be seen in Table 3 and where possible doses were converted to $\mathrm{mg} / \mathrm{kg}$ of Body Weight. Mean and median doses were then used to predict optimal doses for human studies, based on established guidelines for conversion [97, 98]. This was carried out for resveratrol interventions in rat and mouse studies, as only these data contained a large enough number of studies for accurate average and conversion calculations. The mean dose of resveratrol in rats was $53.6 \pm 156.8 \mathrm{mg} /$ $\mathrm{kg}$ (range $1-800 \mathrm{mg} / \mathrm{kg}$ ), with a median dose of $10 \mathrm{mg} /$ $\mathrm{kg}$, which upon conversion produced an estimated human dose of 8.6 and $1.6 \mathrm{mg} / \mathrm{kg}$ for mean and median doses, respectively. In mice, the mean dose was $148+135.2 \mathrm{mg} /$ $\mathrm{kg}$ (range 10-320), with a median dose of $200 \mathrm{mg} / \mathrm{kg}$, which results in an estimated human dose of $12.0 \mathrm{mg} / \mathrm{kg}$ or $11.0 \mathrm{mg} / \mathrm{kg}$ for mean and median doses, respectively. 
Table 3 Study characteristics of animal intervention studies assessing the impact of red wine polyphenols on vascular health and function

\begin{tabular}{|c|c|c|c|c|c|c|c|c|c|}
\hline Authors & Year & Animal & $\begin{array}{l}\text { Disease/clinical } \\
\text { model }\end{array}$ & Supplement & $\begin{array}{l}\text { Dosage (mg/ } \\
\text { kg/day) }\end{array}$ & Duration & Measure & $\begin{array}{l}\text { Healthy } \\
\text { effect } \\
\text { (sig) }\end{array}$ & $\begin{array}{l}\text { Disease } \\
\text { effect } \\
\text { (sig) }\end{array}$ \\
\hline Akar et al. & 2011 & Rabbit & $\mathrm{T} 2 \mathrm{D}$ & Resveratrol & $5(\mathrm{mg} / \mathrm{l})$ & (8-10 weeks) & EVVR & & Yes \\
\hline Akar et al. & 2012 & Rat & FVD & Resveratrol & $50(\mathrm{mg} / \mathrm{l})$ & (10 weeks) & EVVR & & Yes \\
\hline $\begin{array}{l}\text { Aribal-Kocat- } \\
\text { uerk et al. }\end{array}$ & 2009 & Rat & None & Resveratrol & 20 & (24 weeks) & SBP & Yes & \\
\hline Aubin et al. & 2008 & Rat & $\mathrm{HF}$ & Resveratrol & 20 & (8 weeks) & SBP & No & Yes \\
\hline $\begin{array}{l}\text { Bernatova } \\
\text { et al. }\end{array}$ & 2002 & Rat & L-NAME & Provinols & 2.5 & (1-3 weeks) & $\begin{array}{l}\text { SBP and } \\
\text { EVVR }\end{array}$ & & Yes \\
\hline $\begin{array}{l}\text { Behbahani } \\
\text { et al. }\end{array}$ & 2016 & Rat & $\mathrm{SH}$ & Resveratrol & 40 & (10 weeks) & $\begin{array}{l}\text { EVVR and } \\
\text { BP }\end{array}$ & No & Yes \\
\hline Bhatt et al. & 2011 & Rat & SH & Resveratrol & 5 & (10 weeks) & SBP & & Yes \\
\hline Biala et al. & 2010 & Rat & $\begin{array}{l}\text { Transgenic } \\
\text { (Human Renin } \\
\text { and angioten- } \\
\text { sin) }\end{array}$ & Resveratrol & 800 & (4 weeks) & SBP & No & Yes \\
\hline Cheng et al. & 2016 & Rat & FVD & Resveratrol & 10 & (1 week) & $\mathrm{BP}$ & & Yes \\
\hline Cheng et al. & 2013 & Rat & FVD & Resveratrol & 10 & ( $2-4$ weeks) & $\begin{array}{c}\text { SBP and } \\
\text { EVVR }\end{array}$ & & Yes \\
\hline Cheserek et al. & 2016 & Mouse & HFD & $\begin{array}{l}\text { Resveratrol } \\
\text { (and querce- } \\
\text { tin) }\end{array}$ & $\begin{array}{l}60+10(\mathrm{~g} / \mathrm{kg} \\
\text { chow })\end{array}$ & (26 weeks) & EVVR & & Yes \\
\hline da Luz et al. & 2011 & Rat & None & Resveratrol & $\begin{array}{c}4(\mathrm{mg} / \mathrm{kg} \\
\text { chow) }\end{array}$ & (4 weeks) & EVVR & No & \\
\hline Dal-Ros et al. & 2012 & Rat & Ageing & RWP & 100 & (4 weeks) & BP and FMD & & Yes \\
\hline Dolinsky et al. & 2013 & $\begin{array}{l}\text { Rat and } \\
\text { Mouse }\end{array}$ & SH & Resveratrol & $\begin{array}{l}146 \text { (rat) } \\
320 \text { (mice) }\end{array}$ & (5 weeks) & EVVR & & Yes \\
\hline Franco et al. & 2013 & Rat & Obese & Resveratrol & 30 & (30 days) & BP & & Yes \\
\hline Gendron et al. & 2012 & Mouse & Ageing & (+)-Catechin & 0.75 & $\begin{array}{l}(12- \\
36 \text { weeks })\end{array}$ & EVVR & Yes & Yes \\
\hline Gocmez et al. & 2016 & Rat & Ageing & Resveratrol & 15 & (2 weeks) & $\begin{array}{l}\text { SBP and } \\
\text { EVVR }\end{array}$ & No & Yes \\
\hline Gordish et al. & 2016 & Rat & SH & Resveratrol & 146 & (4 weeks) & $\mathrm{BP}$ & No & Yes \\
\hline Hort et al. & 2012 & Mouse & $\begin{array}{l}\text { Transgenic } \\
\text { (LDL Recep- } \\
\text { tor) }\end{array}$ & RWE & $3-30$ & (3 months) & BP & & Yes \\
\hline Inanaga et al. & 2009 & Mouse & $\begin{array}{l}\text { AngII induced } \\
\text { IL-6 expres- } \\
\text { sion }\end{array}$ & Resveratrol & 10 & $\begin{array}{l}\text { ( } 2 \text { and } \\
4 \text { weeks) }\end{array}$ & $\mathrm{BP}$ & No & Yes \\
\hline Jang et al. & 2015 & Rat & $\mathrm{SH}$ & GSE & $15-30$ & (8 weeks) & $\begin{array}{c}\text { SBP and } \\
\text { EVVR }\end{array}$ & & Yes \\
\hline $\begin{array}{l}\text { Jendekova } \\
\text { et al. }\end{array}$ & 2006 & Rat & L-NAME & Provinols & 40 & (4 or 7 weeks) & SBP & & Yes \\
\hline Jiminez et al. & 2007 & Rat & $\mathrm{SH}$ & RWP & 40 & (5 weeks) & EVVR & No & Yes \\
\hline Kavas et al. & 2013 & Rat & None & Resveratrol & 20 & (6 weeks) & $\mathrm{BP}$ & Yes & No \\
\hline Khodja et al. & 2012 & Rat & Ageing & RWP & 100 & ( 2 or 4 weeks) & $\mathrm{BP}$ & No & Yes \\
\hline Kosuru et al. & 2018 & Rat & FVD & Pterostilbene & 20 & (8 weeks) & EVVR & No & Yes \\
\hline Lee et al. & 2017 & Rat & $\begin{array}{l}\text { Spontaneous } \\
\text { Heart Failure }\end{array}$ & $\begin{array}{l}\text { Resveratrol or } \\
\text { pterostilbene }\end{array}$ & 2.5 & (8 weeks) & SBP & No & Yes \\
\hline Louis et al. & 2012 & Rat & Obese & Resveratrol & 2.5 & (4 weeks) & SBP & No & Yes \\
\hline $\begin{array}{l}\text { Majumdar } \\
\text { et al. }\end{array}$ & 2013 & Rat & $\begin{array}{l}\text { Ovariectomy- } \\
\text { induced VD } \\
\text { (+ tobacco } \\
\text { extract) }\end{array}$ & Resveratrol & 50 & (8 weeks) & $\mathrm{BP}$ and $\mathrm{CBF}$ & No & Yes \\
\hline
\end{tabular}


Table 3 (continued)

\begin{tabular}{|c|c|c|c|c|c|c|c|c|c|}
\hline Authors & Year & Animal & $\begin{array}{l}\text { Disease/clinical } \\
\text { model }\end{array}$ & Supplement & $\begin{array}{l}\text { Dosage (mg/ } \\
\mathrm{kg} / \text { day) }\end{array}$ & Duration & Measure & $\begin{array}{l}\text { Healthy } \\
\text { effect } \\
(\text { sig) }\end{array}$ & $\begin{array}{l}\text { Disease } \\
\text { effect } \\
\text { (sig) }\end{array}$ \\
\hline Miatello et al. & 2005 & Rat & FVD & Resveratrol & 10 & (12 weeks) & $\begin{array}{r}\text { SBP and } \\
\text { EVVR }\end{array}$ & No & Yes \\
\hline Mizutani et al. & 2000 & Rat & SH & Resveratrol & 5 & (8 weeks) & EVVR & & Yes \\
\hline Mizutani et al. & 2001 & Rat & $\mathrm{SH}$ & Resveratrol & 1 & (8 weeks) & SBP & & No \\
\hline $\begin{array}{l}\text { Moraloglu } \\
\text { et al. }\end{array}$ & 2012 & Rat & $\begin{array}{l}\text { DOCA-Prec- } \\
\text { lampsia }\end{array}$ & Resveratrol & 20 & (16 weeks) & SBP & & No \\
\hline Mozafari et al. & 2015 & Rat & $\mathrm{T} 2 \mathrm{D}$ & Resveratrol & $5-20$ & (4 weeks) & $\begin{array}{l}\text { SBP and } \\
\text { EVVR }\end{array}$ & & Yes \\
\hline Ozan et al. & 2017 & Rat & FVD & Resveratrol & 10 & (8 weeks) & $\begin{array}{l}\text { BP and } \\
\text { EVVR }\end{array}$ & No & Yes \\
\hline Phyu et al. & 2016 & Rat & $\mathrm{T} 2 \mathrm{D}$ & Resveratrol & 2 & (8 weeks) & SBP & Yes & Yes \\
\hline $\begin{array}{l}\text { Puzserova } \\
\text { et al. }\end{array}$ & 2006 & Rat & Stressed & Provinols & 20 & (8 weeks) & SBP & Yes & No \\
\hline Rezzani et al. & 2009 & Rat & Nephrotoxicity & Provinols & 40 & (3 weeks) & $\begin{array}{c}\text { DBP and } \\
\text { EVVR }\end{array}$ & No & Yes \\
\hline Rivera et al. & 2009 & Rat & Obese & Resveratrol & 10 & (8 weeks) & $\begin{array}{c}\text { SBP and } \\
\text { EVVR }\end{array}$ & No & Yes \\
\hline Robich et al. & 2010 & Swine & $\begin{array}{l}\text { Hypercholester- } \\
\text { olemic }\end{array}$ & Resveratrol & 100 & (11 weeks) & SBP & & Yes \\
\hline Rush et al. & 2007 & Rat & SH & Resveratrol & $\begin{array}{l}0.488-4.48 \\
(\mathrm{mg} / \mathrm{l})\end{array}$ & (4 weeks) & $\mathrm{BP}$ and $\mathrm{CBF}$ & & Yes \\
\hline $\begin{array}{l}\text { Soylemez } \\
\text { et al. }\end{array}$ & 2009 & Rat & None & Resveratrol & $50(\mathrm{mg} / \mathrm{l})$ & (3 weeks) & SBP & Yes & \\
\hline $\begin{array}{l}\text { Thandapily } \\
\text { et al. }\end{array}$ & 2010 & Rat & SH & Resveratrol & 2.5 & (10 weeks) & EVVR & No & No \\
\hline Toth et al. & 2014 & Mouse & Ageing & Resveratrol & 200 & (10 days) & $\mathrm{BP}$ & No & Yes \\
\hline Toth et al. & 2015 & Mouse & $\begin{array}{l}\text { Ageing + Hyper- } \\
\text { tensive }\end{array}$ & Resveratrol & 200 & (10 days) & FMD & & No \\
\hline Ungvari et al. & 2010 & Mouse & $\begin{array}{l}\text { Trans- } \\
\text { genic + HFVD }\end{array}$ & Resveratrol & $\begin{array}{c}2.4(\mathrm{~g} / \mathrm{kg} \\
\text { chow) }\end{array}$ & (16 weeks) & $\begin{array}{l}\text { BP and } \\
\text { EVVR }\end{array}$ & & Yes \\
\hline Wang et al. & 2018 & Mouse & $\mathrm{T} 2 \mathrm{D}$ & Resveratrol & 10 & (4-24 weeks) & SBP & No & Yes \\
\hline
\end{tabular}

Type 2 diabetes (T2D), high fructose vascular dysfunction (FVD), high fat diet (HFD), spontaneously hypertensive (SH), L-NAME induced vascular dysfunction (L-NAME), ex vivo vascular responsiveness (EVVR), systolic blood pressure (SBP), blood pressure (BP), flow mediated dilation (FMD), cerebrovascular blood flow (CBF)

\section{Human studies}

\section{Study characteristics}

Following full-text screening, 42 human studies were identified and included in full data extraction; during which 2 further studies were excluded due to poor study design or a lack of usable primary outcome data $[99,100]$. Of the remaining 40 studies, all were randomised, placebo-control studies, with 14 of these of a cross-over design [16-19, 27, 29-31, 101-106] and 26 of which were parallel arm studies [28, 101, 107-130]. Five studies presented results missing primary outcome data for either pre- or post-trial measures and were contacted to request full details, with data being added to extracted data if provided [107, 111, 120, 131, 132]. In addition, two pairs of studies were found to be using data collected within an identical study cohort, consequentially the data were combined into a single entry in the final dataset [29, 122, 133, 123].

Of the included studies, the majority included a disease/ at-risk cohort, the most common of which were type II diabetes $(n=9)$, obesity $(n=5)$ and metabolic syndrome $(n=4)$, while six studies investigated only healthy controls. The cohort age ranged from 21 to 65 years (mean $=53.5$ years) and studies included both mixed and single sex cohorts (mean $=39.4 \%$ female), with an average BMI of $28.5 \mathrm{~kg} /$ $\mathrm{m}^{2}$ across the full data set. The majority of studies used resveratrol as the supplement intervention $(n=25)$, while only one other study looked at a single RWP in isolation (pterostilbene) [134]. All remaining studies investigated the effects of red wine extract, grape extract, grape seed extract or some modification or combination of these. Five of the 
included studies investigated acute effects $[101,106,110$, $122,132]$, whereas the majority looked at chronic supplementation, of which the most common length was 4 weeks (range $=2-52$ weeks) $[16-19,27-31,103-105,109$, $112-114,116,118,119,121,124,126-130,134,135]$. To discern the potential differences between acute and chronic effects of RWP, these studies were separated for the purpose of analysis. In acute studies, blood pressure was the only outcome measure that could be carried forward for quantitative analysis, due to low numbers of included studies for other vascular measures (FMD, transcranial doppler ultrasound (TCD), etc.), as well as the wide variation in study design used (e.g., supplement used, dose timing, measurement timing, etc.). Quantitative analysis was carried out on chronic studies presenting blood pressure and/or FMD measures, providing full pre- vs. post-supplementation data were available for both control and supplement study arms.

Quality scores revealed a wide range of study quality: despite all studies being randomised, placebo-controlled studies, only $\sim$ half reported details of the randomisation (51\%), concealment (54\%) and blinding method used $(51 \%)$. All studies reported all pre-specified outcome measures, $57 \%$ reported dropout rates and $86 \%$ reported funding sources and potential conflicts of interest. Overall the mean quality score was 4.4 out of a potential total of 7 . The full details of individual scores can be found in Table 4 .

\section{Effect of RWP on blood pressure in humans}

Thirty studies reported measures of blood pressure, of which two were acute supplement studies and 28 were chronic (see Tables 5 and 6). Marques et al. [106] showed no significant effect in systolic or diastolic blood pressure following acute administration of grape extract $(600 \mathrm{mg})$. Wightman et al. [101] also found no significant change in blood pressure with resveratrol alone $(250 \mathrm{mg})$ or with resveratrol combined with piperine $(250 \mathrm{mg}+20 \mathrm{mg})$. The combined effects of the three cohorts reported from these two studies showed an estimated mean difference of $-0.6 \mathrm{mmHg}[-2.4,1.3]$ and $2.0 \mathrm{mmHg}[-0.4,4.4]$ for systolic and diastolic blood pressure, respectively, neither of which was significant and both of which showed high levels of heterogeneity $(p=0.547$; $I^{2}=87.53 \%$, and $p=0.108 ; I^{2}=94.08 \%$, respectively).

Chronic supplementation with a range of RWP resulted in significant changes for measures of systolic (SBP) and diastolic blood pressure (DBP), in 14 and 12 of the included studies, respectively (Table 5). In one study [18], a significant change was seen in the placebo group for DBP, while no significant change was seen in participants supplemented with Muscadine grape seed extract. Of the 28 studies reporting a blood pressure measure, 24 reported pre- and post-trial means for both placebo and intervention groups and were included in quantitative analysis (33
datasets).The remaining 4 studies were not included due to incomplete data (either pre- or post-intervention values not given) for the placebo group [105, 115, 124] or incomplete data in both intervention and placebo groups [16]. Quantitative analysis of pooled data on blood pressure was carried out in 25 studies [17-19, 27-31, 103, 104, 108, $109,112-114,116-119,121,126-130]$, with a total of 33 datasets and standardised mean differences calculated.

\section{Systolic blood pressure}

The overall mean difference following RWP supplementation across all included studies was significant for SBP $\left(-2.6 \mathrm{mmHg},[-4.8,-0.4], p=0.010, I^{2}=99.77 \%\right)$. Subgroup analysis revealed a divergence in effect estimates when healthy and at-risk populations were separated (Fig. 2), with a loss of the significant effect in healthy cohorts $(0.7 \mathrm{mmHg},[-2.5,3.8], p=0.673)$, while a clear significant effect was seen in at-risk populations $(-3.2 \mathrm{mmHg},[-5.7,-0.8], p=0.010)$. No notable difference was seen in heterogeneity in either subgroup $\left(I^{2}=97.56 \%\right.$ and $I^{2}=99.81 \%$, respectively $)$. A sufficient number of studies allowed for the separation of resveratrol trials from the wider pool of studies, with separate analysis of resveratrol and all other studies (i.e., non-resveratrol supplement; see Fig. 3). This subgrouping resulted in the maintenance of a significant mean difference in resveratrol studies $(-3.7 \mathrm{mmHg},[-7.3,-0.0], p=0.047)$, but not in the non-resveratrol supplement groups $(-1.4 \mathrm{mmHg}$, $[-3.4,0.7], p=0.194)$; once again subgrouping had no significant effect on heterogeneity in either group ( $I^{2}=99.63 \%$ and $I^{2}=99.61 \%$, respectively).

Mixed effect modelling was used to evaluate the collective effects of cohort characteristics (health status, age, sex and BMI), as well as the study design used (parallel or cross-over trials and BP measurement method) and showed that these moderators accounted for $53.7 \%$ of heterogeneity, with an omnibus test showing a significant effect for the included moderators $(p<0.001)$. More specifically, health status and measurement method independently accounted for a significant proportion of the heterogeneity (both $p<0.001$ ), while study design bordered on significance $(p=0.051)$.

Additional mixed effect models were used to test the potential collective effects of the type, dose and duration of supplementation interventions, as well as the individual effect of medicine status for the at-risk cohort. Neither of these models showed a significant moderator effect ( $p=0.99$ and $p=0.127$, respectively), although controlling for medication status accounted for $7.7 \%$ of heterogeneity in at-risk cohort studies. 
Table 4 Quality assessment scoring for all human studies included in quantitative data synthesis and analysis, based on the criteria set out in the Cochran Handbook

\begin{tabular}{|c|c|c|c|c|c|c|c|c|c|}
\hline & & $\begin{array}{l}\text { Randomi- } \\
\text { sation }\end{array}$ & $\begin{array}{l}\text { Allocation } \\
\text { concealment }\end{array}$ & Blinding & $\begin{array}{l}\text { Blinding- } \\
\text { outcome }\end{array}$ & $\begin{array}{l}\text { Incomplete } \\
\text { data }\end{array}$ & $\begin{array}{l}\text { Selective } \\
\text { reporting }\end{array}$ & Funding & Overall \\
\hline Barona et al. & 2012 & 0 & 0 & 0 & 0 & 1 & 1 & 0 & 2 \\
\hline Bhatt et al. & 2012 & 1 & -1 & -1 & -1 & 1 & 1 & 1 & 1 \\
\hline Bo et al. & 2016 & 1 & 1 & 1 & 1 & 1 & 1 & 1 & 7 \\
\hline Bo et al. & 2013 & 1 & 1 & 1 & 1 & 1 & 1 & 0 & 6 \\
\hline Botden et al. & 2012 & 1 & 1 & 1 & 1 & 1 & 1 & 1 & 7 \\
\hline Draijer et al. & 2015 & 0 & 0 & 1 & 1 & 1 & 1 & 1 & 5 \\
\hline Evans et al. & 2017 & 1 & 1 & 1 & 1 & 1 & 1 & 1 & 7 \\
\hline Faghihzadeh et al. & 2015 & 1 & 1 & 1 & 1 & 1 & 1 & 1 & 7 \\
\hline Fodor et al. & 2018 & 0 & 1 & 0 & 0 & 0 & 1 & 0 & 2 \\
\hline Fujitaka et al. & 2011 & 0 & 0 & -1 & -1 & 0 & 1 & 1 & 0 \\
\hline Heeboll et al. & 2016 & 0 & 0 & 0 & 0 & 1 & 1 & 1 & 3 \\
\hline Imamura et al. & 2017 & 0 & 0 & 1 & 1 & 1 & 1 & 1 & 5 \\
\hline Khodabandehloo et al. & 2018 & 1 & 1 & 1 & 1 & 1 & 1 & 1 & 7 \\
\hline Kjaer et al. & 2017 & 1 & 1 & 1 & 1 & 1 & 1 & 1 & 7 \\
\hline Lekakis et al. & 2005 & 0 & 0 & 0 & 0 & 0 & 1 & 0 & 1 \\
\hline Marques et al. & 2018 & 0 & 0 & 0 & 0 & 0 & 1 & 1 & 2 \\
\hline Mellen et al. & 2010 & 0 & 0 & 1 & 1 & 0 & 1 & 1 & 4 \\
\hline Movahed et al. & 2013 & 1 & 1 & 1 & 1 & 1 & 1 & 1 & 7 \\
\hline Perez-Jiminex et al. & 2008 & 0 & 0 & 0 & 0 & 0 & 1 & 1 & 2 \\
\hline Ras et al. & 2013 & 0 & 0 & 1 & 1 & 1 & 1 & 1 & 5 \\
\hline Riche et al. & 2014 & 1 & 1 & 1 & 1 & 1 & 1 & 1 & 7 \\
\hline Seyyedebrahimi et al. & 2018 & 1 & 1 & 1 & 1 & 1 & 1 & 1 & 7 \\
\hline Sano et al. & 2007 & 1 & 1 & 0 & 0 & 1 & 1 & 0 & 4 \\
\hline Sivaprakasapillai et al. & 2009 & 0 & 0 & 0 & 0 & 0 & 1 & 1 & 2 \\
\hline Timmers et al. & 2016 & 1 & 1 & 0 & 0 & 0 & 1 & 1 & 4 \\
\hline Timmers et al. & 2011 & 0 & 0 & 0 & 0 & 0 & 1 & 1 & 2 \\
\hline Tome-Carneiro et al. & 2013 & 0 & 0 & 0 & 0 & 0 & 1 & 1 & 2 \\
\hline van der Made et al. & 2017 & 0 & 0 & 0 & 0 & 0 & 1 & 1 & 2 \\
\hline van Mierlo et al. & 2010 & 0 & 0 & 1 & 1 & 1 & 1 & 1 & 5 \\
\hline Wightman et al. & 2014 & 1 & 1 & 1 & 1 & 0 & 1 & 1 & 6 \\
\hline Wong et al. & 2011 & 1 & 1 & 1 & 1 & 0 & 1 & 1 & 6 \\
\hline Wong et al. & 2016 & 1 & 1 & 1 & 1 & 0 & 1 & 1 & 6 \\
\hline Wong et al. & 2013 & 1 & 1 & 1 & 1 & 1 & 1 & 1 & 7 \\
\hline Xue et al. & 2016 & 1 & 1 & 0 & 0 & 0 & 1 & 1 & 4 \\
\hline Yoshino et al. & 2012 & 1 & 1 & 0 & 0 & 1 & 1 & 1 & 5 \\
\hline
\end{tabular}

\section{Diastolic blood pressure}

No significant effects were found in DBP when considering overall effect estimate $(-1.0 \mathrm{mmHg},[-2.2,0.3]$, $p=0.139, I^{2}=99.7 \%$ ), or when subgroup analysis was carried out on resveratrol studies in isolation $(-0.9 \mathrm{mmHg}$, $\left.[-3.2,1.3] ; p=0.417, I^{2}=99.6 \%\right)$. Subgroup analysis based on health status showed no significance in healthy or at-risk cohorts (Fig. 4). Specifically, there were nonsignificant changes in healthy individuals $(0.6 \mathrm{mmHg}$, $\left.[-2.6,3.8], p=0.725, I^{2}=99.0 \%\right)$ and a relative decrease in at-risk cohorts $(-1.2 \mathrm{mmHg},[-2.6,0.2], p=0.08$, $I^{2}=99.7 \%$ ).

Mixed effect models were used to analyse the same moderators as were investigated in SBP and showed similar results. The cohort-study design model accounted for $40.0 \%$ of heterogeneity and this was found to be significant, both overall $(p<0.001)$ and for the health status, BP measurement method and study design moderators individually ( $p<0.001, p=0.032, p=0.023$, respectively). Similarly, the collective supplement moderator model and medicine status model showed no significant impact on heterogeneity 


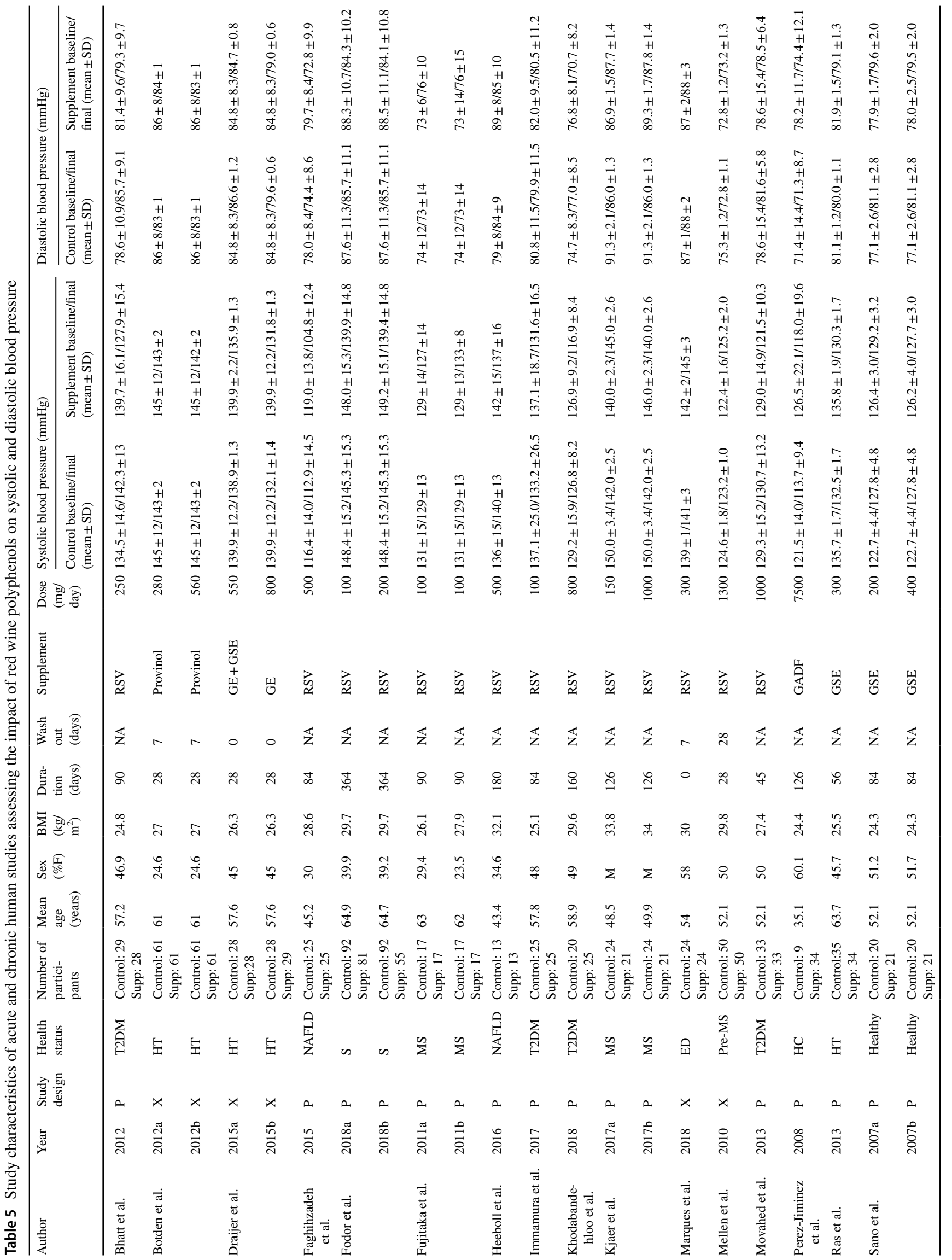




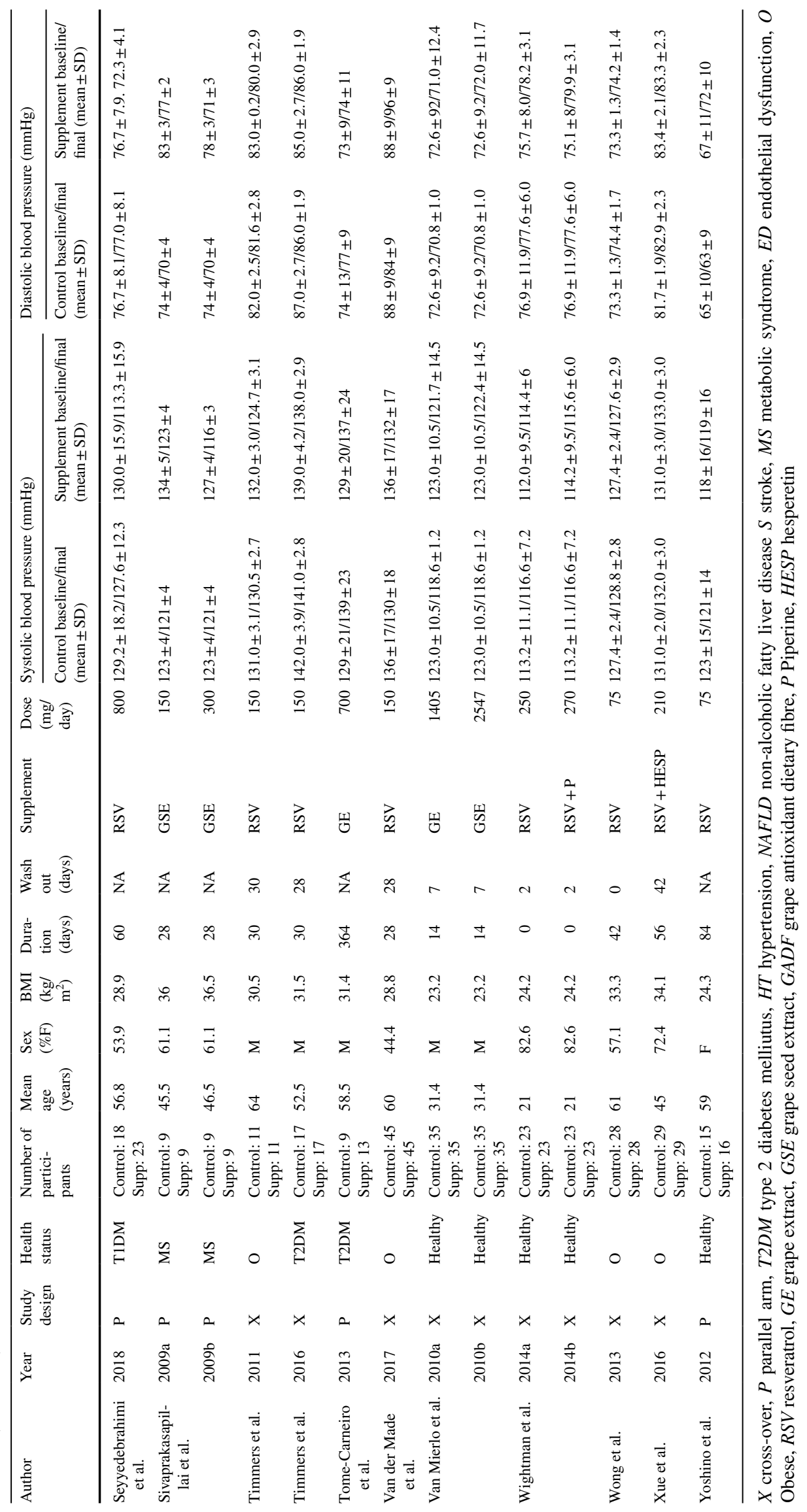




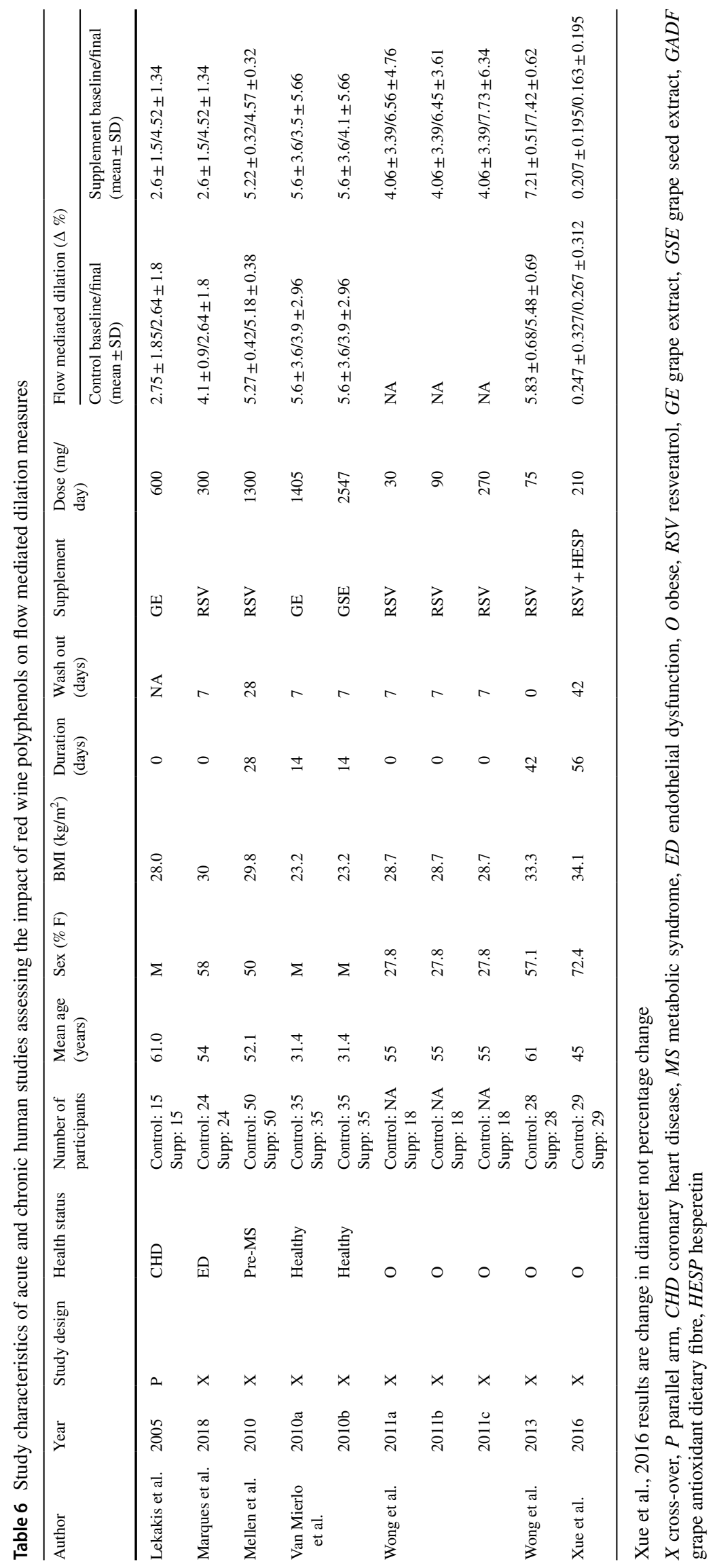




Author(s) and Year Control Supplement $\quad$ Mean Difference $[95 \% \mathrm{CI}]$

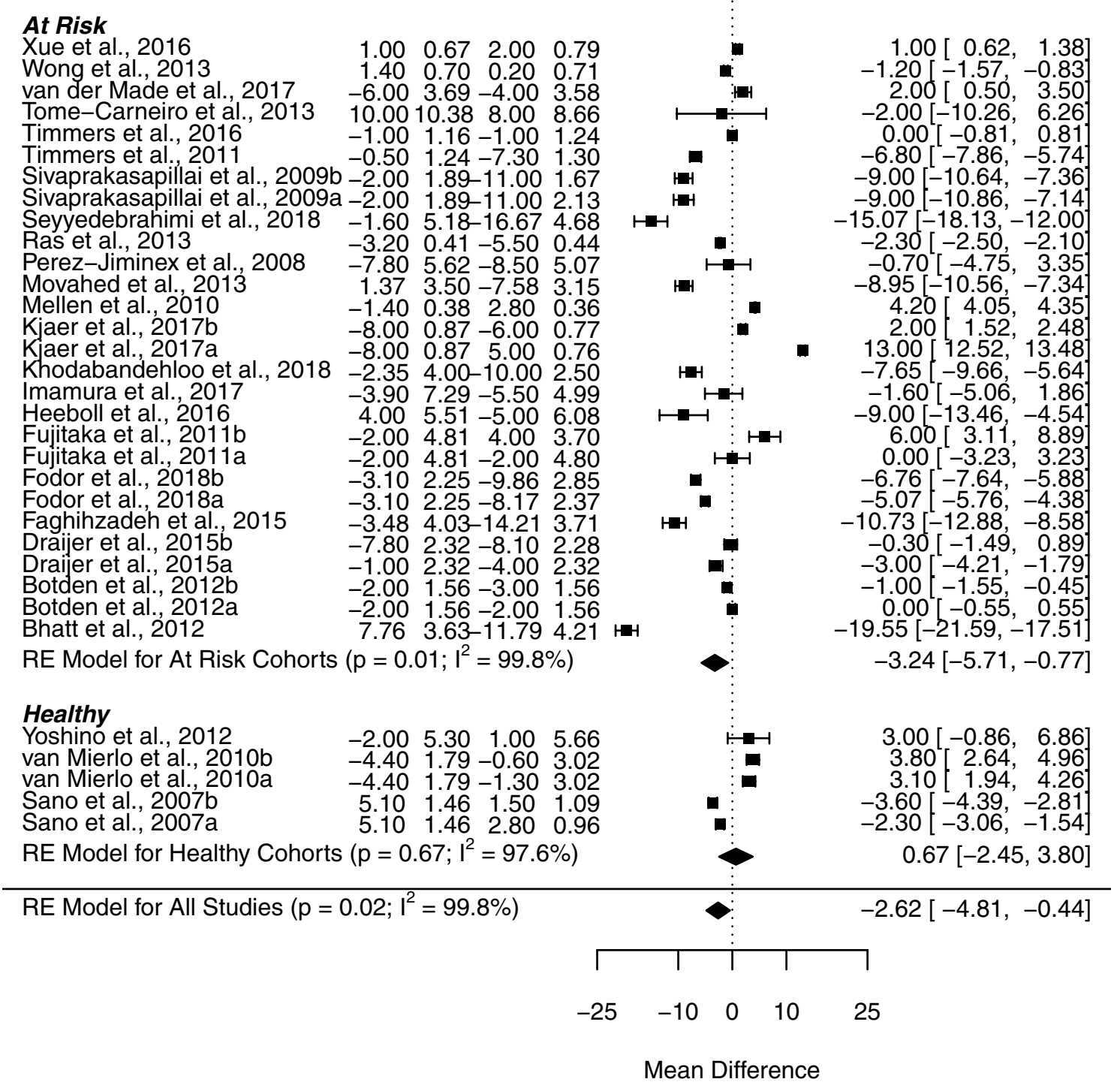

Fig. 2 Forest plot showing mean difference and 95\% confidence intervals for the impact of chronic red wine polyphenol supplementation compared to placebo-controls on systolic blood pressure in humans, with subgroup analysis based on the health status of the included

( $p=0.998 ; p=0.127$, respectively), with medicine status accounting for a small amount of heterogeneity (7.2\%).

\section{Sensitivity analysis}

Sensitivity analysis identified one outlying study that may have a significant influence on the SBP results [117], with a large residual $\left(T^{2}=-3.014\right)$ and model fit impact (DFFITS $=-0.542$, Cook's distance $=0.234$ ), although this outlier had little influence on residual covariance or cohort. Horizontal lines indicate the $95 \%$ confidence interval. Shaded diamond shows the calculated subgroup and overall mean difference alongside the results of the random effect model for each group

heterogeneity (Fig. 5). Model refitting showed a reduction in the overall effect of supplementation when the outlier was excluded, without a loss of significance or notable change in heterogeneity $(-2.1 \mathrm{mmHg},[-4.1$, $\left.-0.1], p=0.036, I^{2}=99.73\right)$. Sensitivity analysis did not reveal any significant outliers for diastolic blood pressure (Fig. 6). Taken in summation, it can be seen that although outlying studies may have been included, these studies did not significantly affect the results of meta-analyses. 


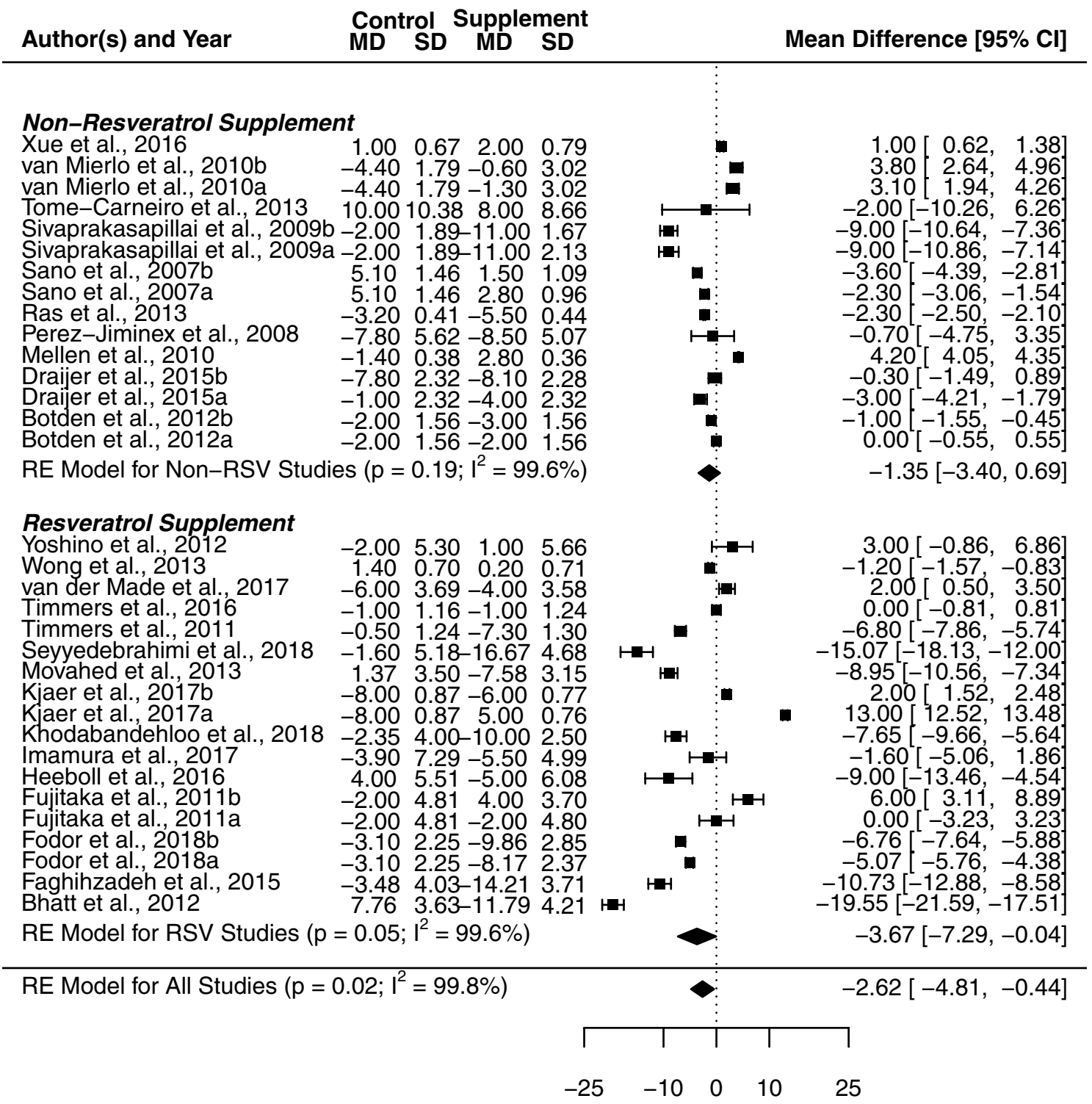

Mean Difference

Fig. 3 Forest plot showing mean difference and 95\% confidence intervals for the impact of chronic red wine polyphenol supplementation compared to placebo-controls on systolic blood pressure in humans, with subgroup analysis comparing studies administering res-

\section{Effect of RWP on vascular function in humans}

\section{Flow mediated dilation}

Peripheral vascular function measures using FMD were reported in 11 studies, of which three were acute interventions $[102,106,110]$ and eight were chronic $[16,18,27$, $31,103,104,128,133]$. The full details for each study are presented in Table 6. All three acute FMD studies showed a significant improvement in the FMD response following veratrol compared to all other red wine polyphenols. Horizontal lines indicate the $95 \%$ confidence interval. Shaded diamond shows the calculated subgroup and overall mean difference alongside the results of the random effect model for each group

resveratrol supplementation across a wide range of doses $(75-2547 \mathrm{mg} / \mathrm{kg} /$ day) $[102,106,110]$, as well as supplementation with whole grape extract [110]. Chronic supplementation with RWP had varying effects across the eight studies: with significant increases reported in two studies [16, 128], a significant decrease reported for one [18] and no effect observed in the remaining five studies $[27,31,103,104$, 133]. Shear rate was also evaluated in three chronic studies with varying results: with no change in two studies $[16,18]$ and an increase in one study [103]. 


\section{At Risk}

Xue et al., 2016

Wong et al., 2013

van der Made et al., 2017

Tome-Carneiro et al., 2013

Timmers et al., 2016

Timmers et al., 2011

Sivaprakasapillai et al., 2009b

Sivaprakasapillai et al., 2009a

Seyyedebrahimi et al., 2018

Ras et al., 2013

Perez-Jiminex et al., 2008

Movahed et al., 2013

Mellen et al., 2010

Kjaer et al., 2017b

Kjaer et al., 2017 a

Khodabandehloo et al., 2018

Imamura et al., 2017

Heeboll et al., 2016

Fujitaka et al., 2011b

Fujitaka et al., 2011a

Fodor et al., 2018b

Fodor et al., 2018a

Faghihzadeh et al., 2015

Draijer et al., 2015b

Draijer et al., 2015a

Botden et al., 2012b

Botden et al., 2012a

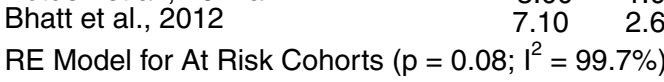

$\begin{array}{rrrr}1.20 & 0.55 & -0.10 & 0.58 \\ 1.10 & 0.40 & 0.90 & 0.36\end{array}$

$\begin{array}{rrrr}-4.00 & 1.90 & -2.00 & 1.90\end{array}$

$\begin{array}{lrrr}3.00 & 5.27 & 1.00 & 3.94\end{array}$

$\begin{array}{rrrr}-1.00 & 0.80 & 1.00 & 0.80\end{array}$

$\begin{array}{llll}-0.40 & 1.13 & -3.00 & 0.88\end{array}$

$\begin{array}{llll}-4.00 & 1.89 & -7.00 & 1.41\end{array}$

$\begin{array}{llll}-4.00 & 1.89 & -6.00 & 1.20\end{array}$

$\begin{array}{llll}0.33 & 2.69 & -4.36 & 1.86\end{array}$

$\begin{array}{rrrr}-1.10 & 0.28 & -2.80 & 0.34\end{array}$

$\begin{array}{llll}-0.10 & 5.61 & -3.80 & 2.89\end{array}$

$\begin{array}{llll}2.97 & 2.87 & -0.04 & 2.90\end{array}$

$\begin{array}{llll}-2.50 & 0.23 & 0.40 & 0.25\end{array}$

$\begin{array}{llll}-5.30 & 0.51 & -1.50 & 0.48\end{array}$

$\begin{array}{llll}-5.30 & 0.51 & 0.80 & 0.45\end{array}$

$\begin{array}{llll}2.38 & 2.66 & -6.13 & 2.30\end{array}$

$\begin{array}{rrrr}-0.90 & 3.25 & -1.50 & 2.94\end{array}$

$\begin{array}{llll}5.00 & 3.34 & -4.00 & 3.55\end{array}$

$\begin{array}{llll}-1.00 & 4.47 & 3.00 & 4.98\end{array}$

$\begin{array}{llll}-1.00 & 4.47 & 3.00 & 2.83\end{array}$

$\begin{array}{llll}-1.94 & 1.65 & -4.37 & 2.09\end{array}$

$\begin{array}{llll}-1.94 & 1.65 & -4.02 & 1.64\end{array}$

$\begin{array}{llll}-3.62 & 2.41 & -6.84 & 2.60\end{array}$

$\begin{array}{llll}-5.20 & 1.57 & -5.80 & 1.55\end{array}$

$\begin{array}{llll}1.80 & 1.58 & -0.10 & 1.58\end{array}$

$\begin{array}{llll}-3.00 & 1.03 & -3.00 & 1.03\end{array}$

$\begin{array}{llll}-3.00 & 1.03 & -2.00 & 1.03\end{array}$

$\begin{array}{ll}-2.14 & 2.58\end{array}$

\section{Healthy}

Yoshino et al., 2012

van Mierlo et al., 2010b

van Mierlo et al., $2010 a$

Sano et al., 2007b

Sano et al., 2007a

RE Model for Healthy Cohorts $\left(p=0.72 ; I^{2}=99.0 \%\right)$

$$
\begin{array}{rr}
-2.00 & 3.47 \\
-1.80 & 1.56 \\
-1.80 & 1.56 \\
4.00 & 0.85 \\
4.00 & 0.85 \\
& \left.; l^{2}=99.0 \%\right)
\end{array}
$$

RE Model for All Studies $\left(p=0.14 ; I^{2}=99.7 \%\right)$
$-0.60$

$-1.60$

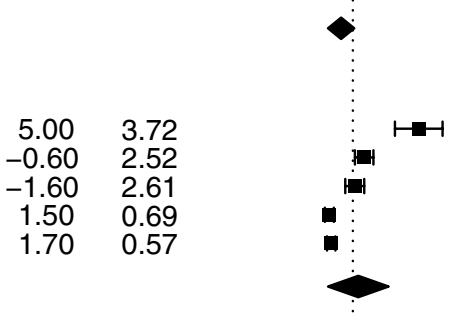

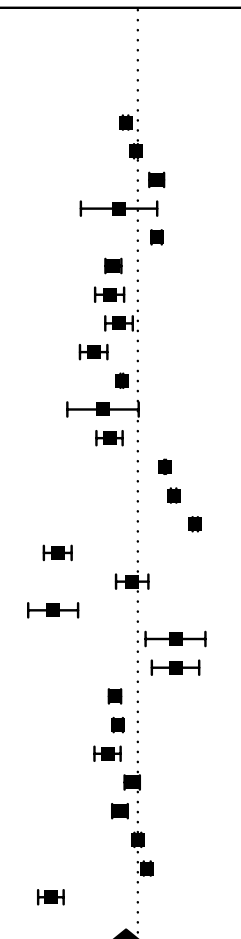

$-1.30[-1.59,-1.01]$

$-0.20[-0.40,0.00$

$2.00[1.22,2.78]$
$-2.00[-6.06,2.06]$

$2.00[1.46,2.54$

$-2.60[-3.45,-1.75]$

$-3.00[-4.54,-1.46]$

$-2.00[-3.46,-0.54]$

$-4.69[-6.15,-3.24$

$-1.70[-1.85,-1.55]$

$-3.70[-7.49,0.09]$

$-3.01[-4.40,-1.62]$

2.90 [ $2.81,2.99$

$3.80[3.51,4.09]$

$6.10[5.82,6.38]$

-8.51 [ -9.98, -7.04]

$-0.60[-2.32,1.12]$

$-9.00[-11.65,-6.35]$

$4.00[0.82,7.18$ ]

$4.00[1.48,6.52]$

$-2.43[-3.08,-1.78$

$-2.08[-2.57,-1.59$

$-3.22[-4.61,-1.83]$

$-0.60[-1.41,0.21]$

$-1.90[-2.73,-1.07]$

$0.00[-0.37,0.37]$

$1.00[0.63,1.37$

$-9.24[-10.59,-7.89]$

$-1.25[-2.65,0.15]$

$7.00[4.47,9.53]$

$1.20[0.22,2.18]$

$0.20[-0.81,1.21]$

$-2.50[-2.98,-2.02]$

-2.30 [ -2.75, -1.85]

$0.58[-2.64,3.80]$

$-0.97\left[\begin{array}{ll}-2.25, & 0.31]\end{array}\right.$

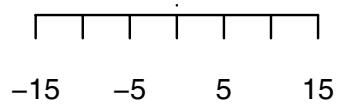

Mean Difference

Fig. 4 Forest plot showing mean difference and 95\% confidence intervals for the impact of chronic red wine polyphenol supplementation compared to placebo-controls on diastolic blood pressure in humans, with subgroup analysis based on the health status of the included cohort. Horizontal lines indicate the $95 \%$ confidence interval; shaded diamond shows the calculated subgroup and overall mean difference alongside the results of the random effect model for each group
Quantitative analysis was carried out on the four studies for which full pre-post, placebo-supplement data were available [18, 27, 103, 104]. Random effects modelling estimates showed no significant mean difference between placebo and intervention supplements $(-1.08,[-4.57$, $2.41], p=0.544, I^{2}=99.40 \%$ ). Health status was evaluated as a potential moderator by mixed effect modelling and showed that this accounted for $72.5 \%$ of heterogeneity $(p=0.002)$. Sensitivity analysis revealed one potentially influential outlier [18], which showed a large residual $(-3.844)$, as well as a notable impact on model fit $($ DFFITS $=-1.883$, Cook's distance $=0.813)$ and residual covariance (cov. $r=0.271)$. Model refitting excluding this outlier resulted in reversal of the effect of supplementation over placebo, but no change in significance $(0.526$, $[-1.291,2.343], p=0.570)$, meaning that although this study impacted the trend seen it did not result in a loss of a significant overall effect. 

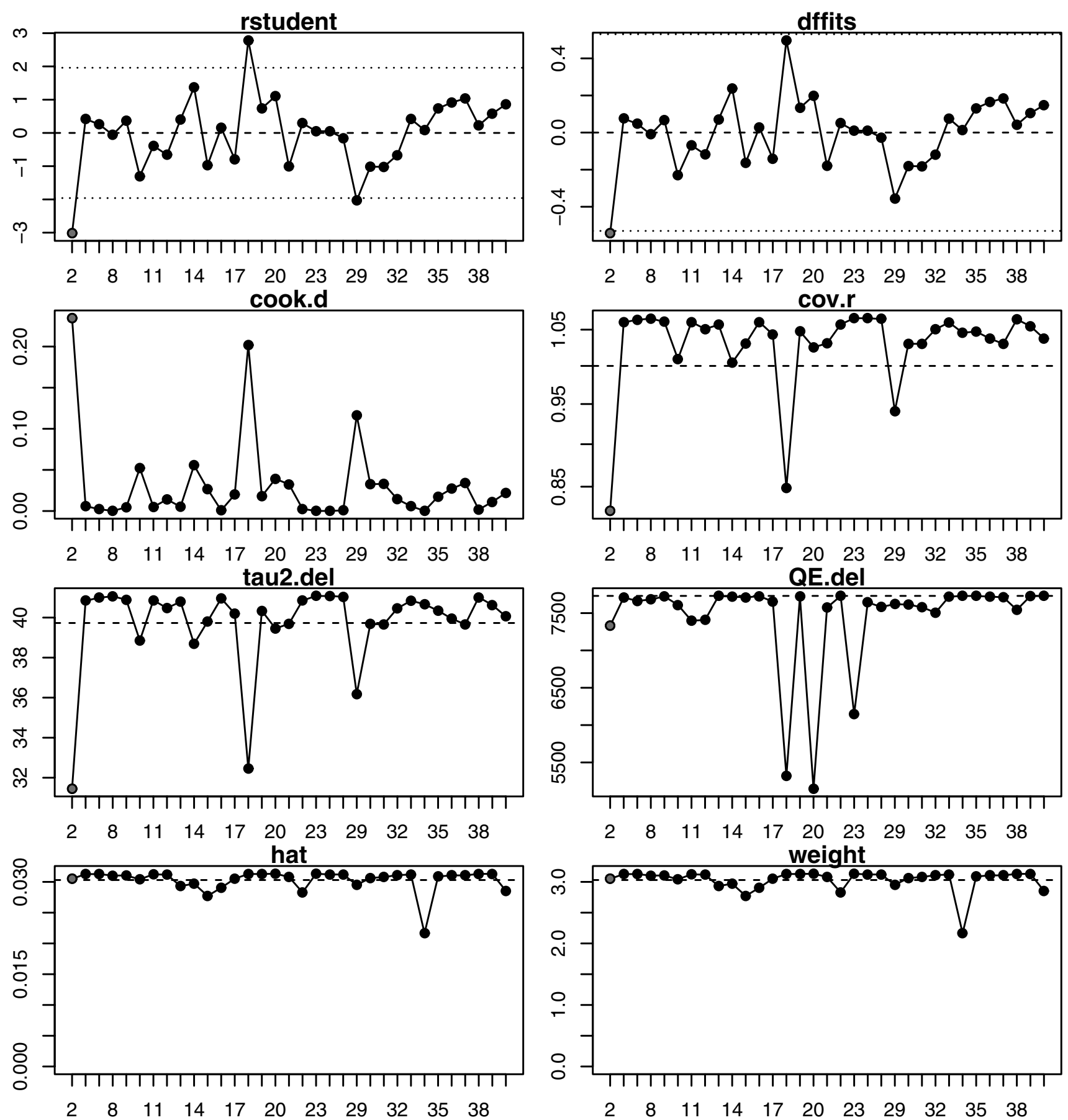

Fig. 5 Sensitivity and influence analysis computed using the Metafor meta-analysis package for human studies included in meta-analysis for systolic blood pressure, showing the externally standardised residuals (rstudent), standard deviation fits (DFFIT), Cook's distances (cook.d), covariance ratios (cov.r), leave-on-out estimates of the

amount heterogeneity (tau2.del), leave-one-out values of the test statistics for heterogeneity (QE.del), hat values (hat) and weight weight). Studies presented in red are considered influential and should be inspected on a case-by-case ratio to determine whether they may be considered an outlier

\section{Cerebrovascular function}

Only two studies were found that measured cerebrovascular function, both of which assessed function using transcranial

Doppler ultrasound measures of resting blood velocity in response to resveratrol $[122,125]$. Of these, one aimed to determine the acute response to a single dose of resveratrol 75 min prior to assessment [122], whereas the other looked 

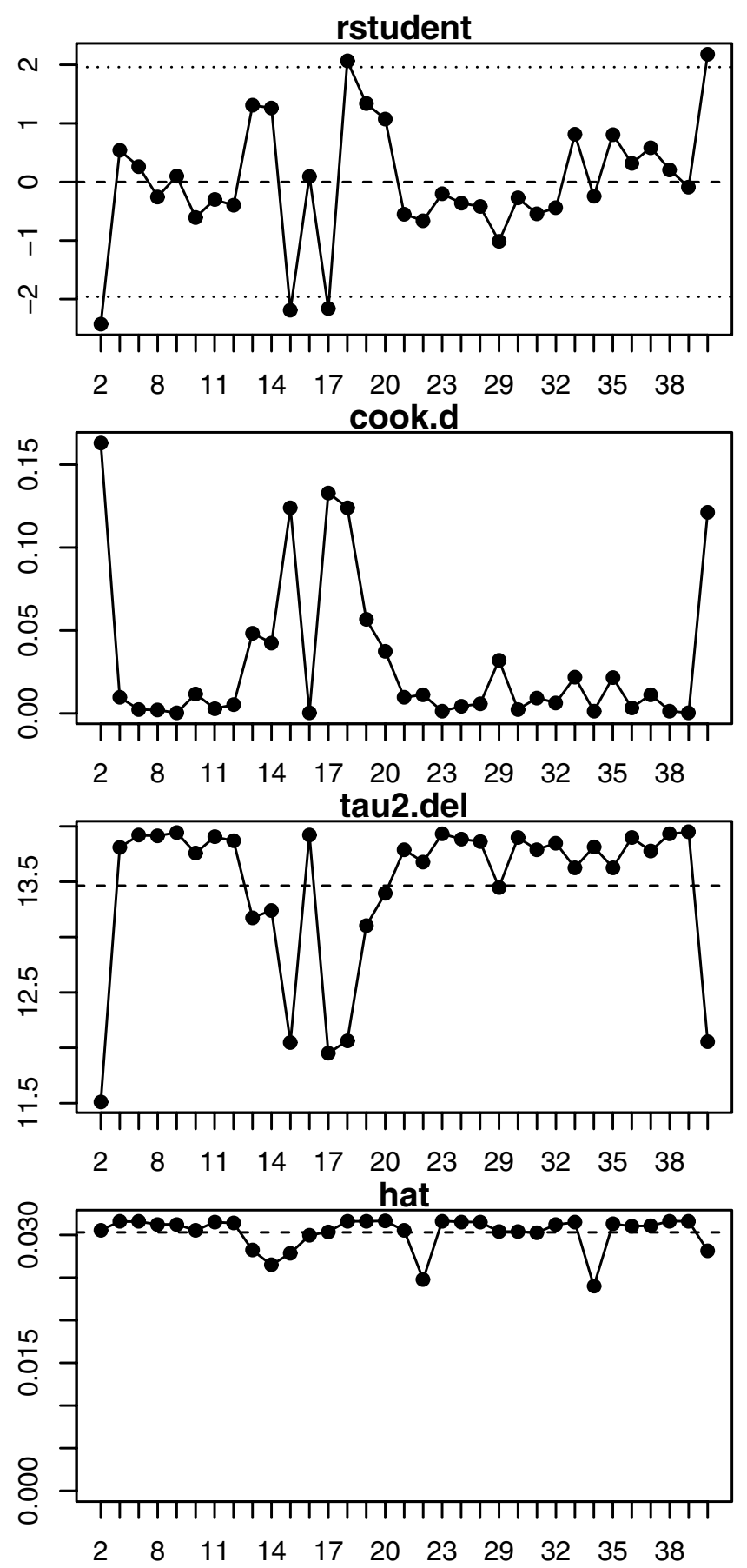

Fig. 6 Sensitivity and influence analysis computed using the Metafor meta-analysis package for human studies included in meta-analysis for diastolic blood pressure, showing the externally standardised residuals (rstudent), standard deviation fits (DFFIT), Cook's distances (cook.d), covariance ratios (cov.r), leave-on-out estimates

at the response to 12 weeks of supplementation in comparison to a placebo control [125], so comparison of results was not possible. Wong et al. [122] examined acute effects in type 2 diabetics at both high and low doses of resveratrol $(75,150$ and $300 \mathrm{mg})$, reporting significant improvements
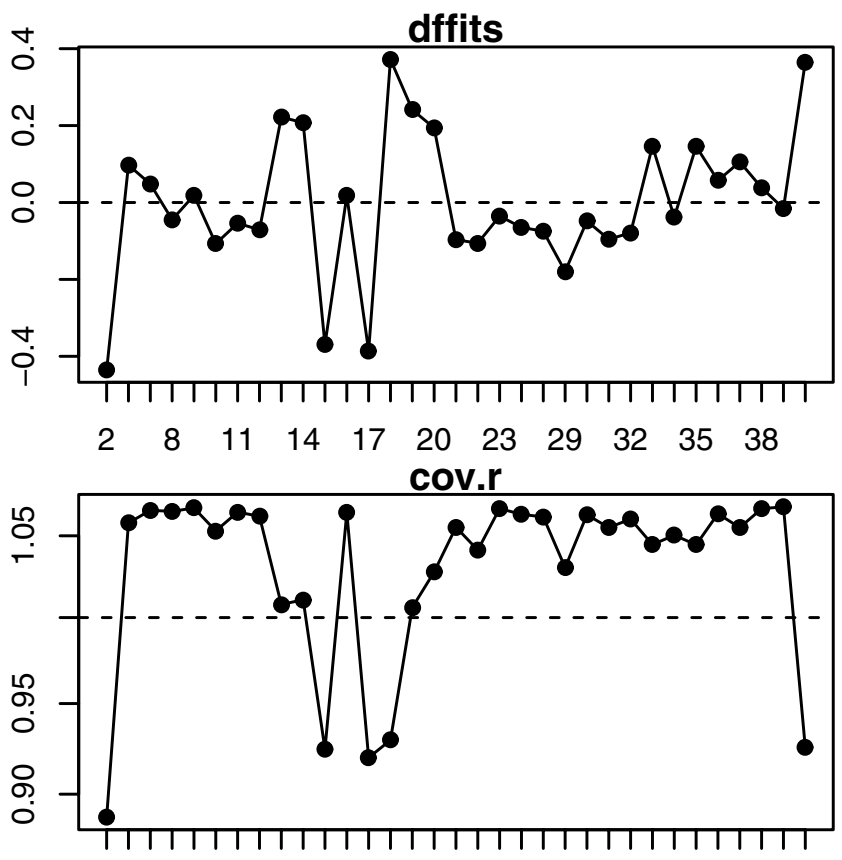

$\begin{array}{lllllllllll}2 & 8 & 11 & 14 & 17 & 20 & 23 & 29 & 32 & 35 & 38\end{array}$
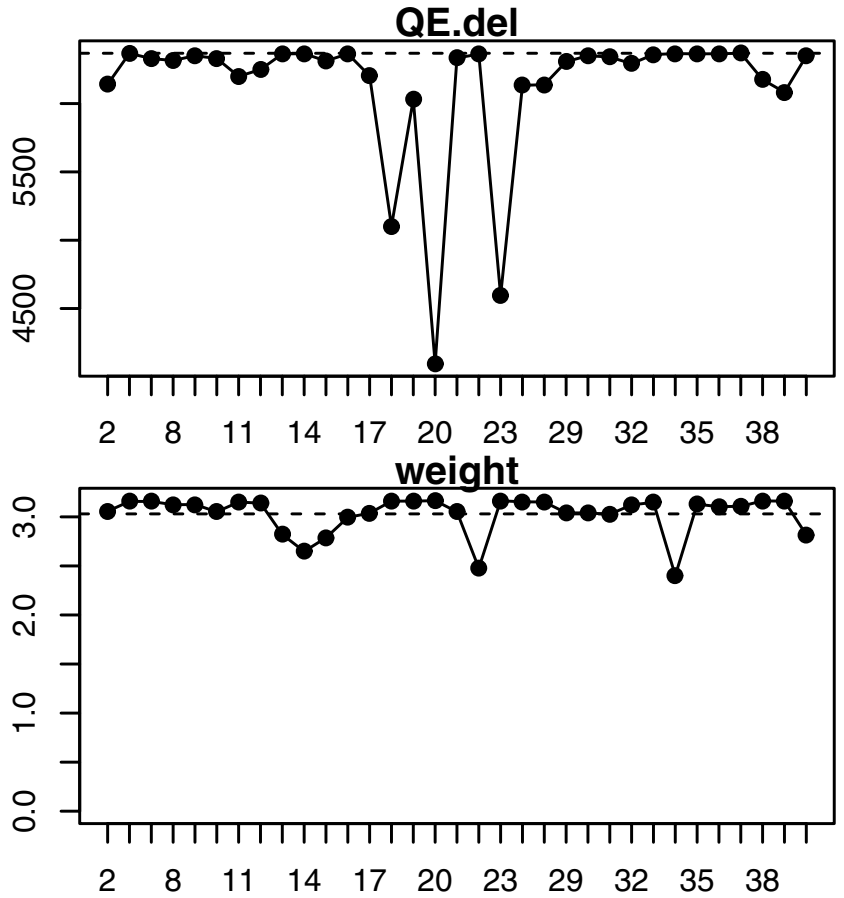

of the amount heterogeneity (tau2.del), leave-one-out values of the test statistics for heterogeneity (QE.del), hat values (hat) and weight (weight). Studies presented in red are considered influential and should be inspected on a case-by-case ratio to determine whether they may be considered an outlier

in middle cerebral artery velocity (MCAv) for all doses, while only low-dose resveratrol resulted in a significant improvement in posterior cerebral artery velocity (PCAv). Moreover, Evans et al. [125] showed that chronic (14 weeks) of resveratrol $(150 \mathrm{mg} /$ day $)$ supplementation in a cohort 
of postmenopausal women significantly increased MCAv response to hypercapnia (i.e., cerebrovascular responsiveness), without a significant increase in resting MCAv.

\section{Discussion}

\section{General findings}

This review aimed to determine the effects of RWP on vascular health, as well as examining the impact of health status and population characteristics on vascular outcomes in both animals and humans. The resulting data showed efficacy within animal models, while human studies displayed larger amounts of variability, which was partly accounted for by known causes of heterogeneity. Overall, the majority of the current literature on RWP was focused on whole grape, seed or skin extracts, or resveratrol in isolation. There was a significant dichotomy in the number of studies between blood pressure and more specific measures of vascular function (e.g., ultrasound measures of flow mediated dilation and cerebral blood flow); likely due to the more time-consuming and technically demanding methods used to assess function. The predominant outcome from the meta-analyses was a significant reduction in SBP within clinical populations, while DBP showed a non-significant reduction following supplementation and compared to placebo cohorts. The following discussion will assess the potential of RWP to have a beneficial effect in vascular health, both generally and in regards to differences seen across different populations and RWP interventions.

\section{Blood pressure}

The findings of the meta-analysis indicated that RWP and isolated grape polyphenol have the capacity to significantly improve SBP beyond the clinical threshold for meaningful effects $(-2 \mathrm{mmHg})$. The results further indicate that supplementation with resveratrol in isolation may be more effective than supplementation with whole grape or grape seed extract in improving blood pressure. However, this comes with a significant caveat that very high levels of heterogeneity are observed across the studies that have reported SBP as an outcome measure. Although this review did not restrict the type of intervention given, as has been previously described $[15,40,136]$, this potential issue was addressed by subgroup analysis of resveratrol alone, alongside meta-regression to investigate supplement type as a moderator; neither of which showed a significant reduction in heterogeneity. Furthermore, despite the greater level of heterogeneity seen in this meta-analysis, the overall findings are in agreement with those reported in previous studies of grape polyphenols and resveratrol $[15,40,136]$.
No significant overall effect was found in diastolic blood pressure, although reductions in blood pressure approached significance in the non-healthy sub-group. These findings are consistent with previous reviews in resveratrol [40], but not grape seed extract [15]. The dichotomy between SBP and DBP may be the result of relatively smaller changes in DBP seen in clinical hypertension and the greater the potential impact of heterogeneity between studies as a result of this smaller changes [137]. In addition, within the review by Zhang et al. [15] significance was only maintained in early stage hypertension and "other" clinical studies within subgroup analyses, highlighting the limited consistent findings within this measure. Although both systolic and diastolic blood pressure are indicative of increased morbidity, changes in SBP are considered to be of greater risk in hypertension and CHD [138]. Taken together, these findings indicate that RWP supplementation may be effective at treating hypertension regardless of the lack of consistent responses on DBP.

Importantly, significant heterogeneity was observed across the literature and a number of studies showed an increase in SBP with supplementation, albeit non-significant. Subgroup and meta-regression analysis found no clear pattern with disease type, medication or participant characteristics, indicating that there are unaccounted moderators causing the significant variability in the intervention effects reported. One factor that may have contributed to the large level of heterogeneity may be associated with the variability between placebo and intervention arms at baseline. One likely cause of such variability may related to studies in which blood pressure was not a primary outcome measure; if randomisation was stratified against another outcome measure that could lead to differences in baseline blood pressure between groups. Alternatively, randomisation was not controlled for and this variability is the result of chance, potentially linked to the large number of outcome measures included in some studies. Although BP differences at baseline were not statistically significant in any of the studies considered, they can be considered clinically relevant (>3 mmHg) in some cases (within the range of the average effect seen under statin treatment $[139,140])$. This is a key point that should be taken into consideration in future studies, given that clinically relevant differences in baseline BP measures may increase the risk of type II errors and can be avoided by stratifying randomisation against multiple baseline measures, as opposed to uncontrolled or sex-based stratified randomisation [141].

\section{RWP and vascular function}

The present analysis indicates that RWP supplementation does not result in any significant changes in peripheral vascular function as measured by brachial FMD, with only one 
study reporting a significant decline in vasodilation following RWP supplementation [18]. Interestingly, this study also showed a significant increase in SBP over 4-weeks of grape seed extract supplementation, indicating that the supplementation had a deleterious effect on the population in this case [18]. Despite the current lack of consistent findings in regards to vascular function, the reported NO-dependent mechanism of action of RWP and more specifically resveratrol [142], would suggest that improvements in measures such as FMD would be expected alongside improvements in blood pressure.

A small number of studies have investigated the specific role of RWP in the cerebrovasculature, with resveratrol supplementation leading to a significant improvement in cerebrovascular function in both studies [122, 125]. The limited number of studies and lack of studies outside of isolated resveratrol supplementation restricts the conclusions that can be drawn regarding cerebrovascular response and warrants further investigation. A direct comparison between the effects of supplementation on the different vascular beds will help to determine whether RWP effects are indeed distinct across vasculatures, or due to limitations of the experimental approaches used to detect the response to RWP supplements.

\section{Animal study results and transition into humans}

Findings from animal studies consistently demonstrated significant improvements in both blood pressure and vascular function in disease models across a wide variety of supplement types and pathologies. In particular, studies into the effects of RWP on vascular responsiveness showed improved vasodilatory response in excised arterial rings in all cohorts, regardless of disease model or species $[6,8,10,58,60,65$, $67,78,85,87-89,92,96,143,144]$. In regards to effects on blood pressure, the large majority of studies showed significant improvements (84\%) [6, 7, 9, 57-60, 64, 67, 73, 77-79, $82-86,88,93,95,144-150]$, while a smaller number of studies did not show any beneficial response to supplementation. Interestingly, in all studies showing no significant improvement in blood pressure [69, 70, 75, 81, 94], a significant improvement was seen in vascular responsiveness, indicating that supplementation did have an effect within the vasculature despite no significant changes in blood pressure being found. In the three studies involving hypertensive models that saw no significant improvement [69, 81, 94], no consistent pattern was seen in regards to study duration, dosage, supplement type or animal model used, which could explain the differences seen between these studies and the majority of findings.

Consistent effects were not seen in healthy animals, with less than half of studies showing a beneficial change in blood pressure and vascular responsiveness outcomes following supplementation. This indicates that even in the highly controlled environment in which animals are raised, RWP have limited potential to improve vascular health or function above the 'healthy physiological normal'. This generally agrees with what has been reported in human studies, in which no significant impact was seen across healthy cohorts.

The lack of reproducibility from animal models to humans is well documented and is by no means unique to nutrition research [151]. This is clearly visible within this review, wherein despite similar trends in regards to the benefit in healthy and at-risk populations, the response to RWP in at -risk and disease populations was markedly more consistent in animal models than in human studies. Broadly speaking the potential causes of this variation fall into three categories: (i) issues in effectively transitioning animal-model research into humans; (ii) the condition differences in which studies can and are conducted between animals in captivity and humans; and (iii) the biological differences between animals and humans. One of the most common issues to be considered in study designs when trying to emulate animal model results in humans is that of dosage. Traditionally when transitioning from animal to human models, it was common practice to directly translate dosage in milligrams per kilogram of body mass. However, it has now been shown that due to the higher metabolic rate in smaller animals a more appropriate method is to convert doses based on body surface area (BSA) [97]. Within the studies included in this review, the dose administered varied widely across both human and animal studies, highlighting there is as yet no clear consensus on optimal dosage in either field. When resveratrol doses were compared between rodents and humans, median doses were greater in humans when compared to rats (conversion ratio 1:6.2), but lower than that used in mice $(1: 12.3)$ [97, 98]. Given the similarity in results between rats and mice, these results would indicate that either the dosage used in mouse studies is in excess of what is required to see an effect, or that a significant variation in responses is seen between species. If the latter is the case then the same may be true when comparing humans to animal models and future research must establish the dose response curve in humans specifically, rather than relying on dose conversion from animal studies. In addition, it should be noted that future studies in animals need to establish clear optimal doses to exclude variability in dosage as a potential cause for variability in outcome.

Greater variability in outcome measures of human studies is to some degree unavoidable, as replicating the level of control experienced in animal studies is near impossible in a free-living population of humans. Furthermore, the introduction of dietary polyphenols into an animal population can be guaranteed to be novel, as chow diets can be ensured to be free of these compounds. In humans consumption during intervention can be controlled to some extent, however, adherence to polyphenol 
free conditions is likely to be as problematic as adherence to other dietary interventions [37,38], while controlling for lifetime consumption is simply not possible. This might result in a fundamental difference in the physiological response in humans and animals, given that rodent models are being exposed to these compounds for the first time, whereas humans are likely to have been previously exposed to them and may have variable responses dependent on their dietary background. In addition, despite the present review including only animal studies in which supplementation was carried out through oral administration, differences in compound delivery still occur: e.g., through oral gavage [60], incorporation into chow [89], or via drinking water [152], which ultimately will cause inter- and intra-subject variability in the dose consumed and its bioavailability.

Furthermore, distinct absorption and metabolism are likely key determinants of the variability in physiological responses to dietary polyphenols across species. Generally, polyphenols have poor bioavailability in their original form and are dependent on the activity of circulating metabolites to elicit beneficial effects $[34,153]$. The complex metabolic fate of combined RWP [154] within human populations, alongside the dependence on the lower digestive tract for absorption [34], highlights the potential for variability between bioavailability humans and animal models. Direct comparison of metabolic fate between humans and rodents of the dietary polyphenol epicatechin found in grapes, as well as in high levels in dark chocolate, demonstrated the striking differences that can be found when determining metabolic fate [155]. Furthermore, Ottaviani et al. [155] also highlighted the importance of gut microbiota in defining this fate, as large changes in circulating metabolites occurred following sufficient time for the dose to the colon. Clear differences have also been found in the metabolic fate of resveratrol and pterostilbene (a dimethyl analog of resveratrol), due largely to significant differences in the microbial biotransformation of both polyphenols prior to absorption into the blood stream [156]. Once again indicating that the differences in gut microbiota between species can have a significant impact on the impact of dietary polyphenols.

Although animal models do provide unique opportunities to explore the mechanistic and structural responses to RWP supplementation, the differences between animal models and free living humans dictate that findings from these models cannot readily predict responses in human populations [157]. To maximise the potential for human studies to replicate the results seen in animals, researchers must ensure adherence to both intervention and dietary restrictions are monitored closely and undertaken further work to establish the differences in biological response under supplementation.

\section{Causes of heterogeneity}

The large level of heterogeneity within this meta-analysis was not unexpected, particularly when considering the data as a whole, since multiple types of interventions (pure polyphenols and more complex extracts) were included, as well as various vascular dysfunctions associated with "at-risk" populations. However, meta-regression results based on the moderators identified in previous meta-analyses accounted for just over half of variability between studies, with no significant heterogeneity accounted for by dose and duration of intervention, which have previously been reported as major sources of heterogeneity $[15,40]$. Disease characteristics appear to be responsible for the largest proportion of accountable heterogeneity, despite the similarity in causes of vascular endothelial dysfunction between many of the included diseases [158-160].

Given the impact of disease characteristics and the lack of effect when controlling for medication, it may be that there is an unknown interaction between the specific treatments for each condition and RWP supplementation, which could go some way as to explain the lack of significant interaction with medication status. Alternatively, the wide variety of vascular-linked diseases and the wide variations in the symptoms presented by each disease may all alter the response to RWP supplementation. Regardless, it does appear that the response to RWP supplementation is highly variable across different pathologies and this must be taken into account when considering the efficacy for supplementation within a given cohort.

\section{Whole extracts or isolated components}

To the best of our knowledge, this is the first review, that has sought to directly compare the vascular response to whole RWP interventions with pure resveratrol, both of which have been suggested to have vasoprotective properties [23, 24]. The results of this meta-analysis indicated that resveratrol alone produces similar vascular responses to those seen in whole grape and grape seed extract supplements. Furthermore, resveratrol seems to produce more consistent results than those seen in whole extracts, as indicated by the greater effect size and lower number of equivocal findings. There are clear benefits to supplementation with resveratrol in isolation, as it is purified and produced at a given concentration per dose. Whole extracts can vary in the relative content of individual components and optimal dosage will vary dependent on grape variety and extraction process. It should be noted that there are potential issues with resveratrol supplementation, as research has highlighted that although oral absorption is relatively high, the bioavailability of resveratrol in the blood stream was low [161]. Conversely, there are additional stilbene compounds, such as pterostilbene, 
that exhibit similar effects as resveratrol while displaying improved bioavailability [162].

\section{Recommendations for future studies}

Before recommendations can be made regarding any form of RWP supplement, further research should be conducted to determine the efficacy, optimal dose and minimum duration for that supplement within a target cohort. The studies included in this review demonstrate the lack of a clear consensus on dosage, as even single supplement studies demonstrated a wide dosage range. For example, resveratrol was administered at a minimum dose of $75 \mathrm{mg} / \mathrm{day}[28,103]$ and a maximum of $1000 \mathrm{mg} /$ day $[109,112]$.

Alongside the need for greater clarity on dose and duration responses, future studies must look to determine the specific interaction of different medications. Indeed, our analysis indicates that only taking into consideration whether a participant cohort is taking medication does not appear to explain the differences in outcomes observed between studies. Future studies should also look to determine the efficacy of other stilbenes and polyphenols in improving vascular function, given that resveratrol is one of many potentially vasoactive components found in red wine and grape extracts. To better determine the effects of RWP in vascular dysfunction, more research that is less reliant on measures of blood pressure alone is needed, as a loss of vascular responsiveness is also an essential component of disease risk and at present there is a notable shortage of studies identifying peripheral and cerebral vascular function changes with RWP supplementation. In addition, Gliemann et al. [163] demonstrated that the adaptation response to regular exercise was blunted with resveratrol supplementation in older men and further studies are essential to determine if this is an issue with resveratrol and RWP supplementation in general, as regular exercise has been consistently shown to improve vascular health and risk factors [164].

\section{Limitations}

In this meta-analysis a large amount of heterogeneity was accounted for as a result of specific data on disease status and disease type. $\mathrm{H}$, detailed meta-regressions were not possible with regards to medication status, as the data available only indicated whether a cohort as a whole was medicated. Due to the large number of health conditions within the included studies and the potential variation in interaction effects with each prescribed medication, it was not possible to determine the impact of specific medicines on the effects of a given supplement and to do so would increase the risk of type I error [51]. In future, reviewers will need to establish a method for addressing or identifying the interaction of specific medications with a given supplement to control for this moderator across a wide range of populations, or alternately determine the interaction effect within a less varied population with a smaller number of potential medications. Secondly, full comorbidity and multimorbidity data were not extracted from included studies, which prevented us from assessing the impact that this had on results and heterogeneity. Future studies will need to determine how this can be done as vascular dysfunction rarely appears in isolation and a number of diseases are characterised by the accumulation of multiple conditions (e.g., metabolic syndrome), making differentiating between primary disease and comorbidity difficult. Finally, due to the low number of studies in peripheral and cerebral vascular function, only basic effect size could be calculated for FMD outcome measures. As such, limited conclusions could be drawn and it was not possible to identify potential moderators with regards to vascular responsiveness measures.

\section{Conclusion}

This review has shown that RWP supplementation has the capacity to improve SBP in human clinical populations, but with no clear response in DBP and vascular function (as measured by brachial FMD). Furthermore, we have shown that pure resveratrol was as effective as whole RWP extract supplementation in improving blood pressure and vascular function. Animal models, most of which were rodent models of disease, have shown a consistent and large response in all markers of blood pressure and in vitro and in vivo vascular function. In comparing human and animal data, although some of the beneficial responses seen in rodent models appear to be carried over into humans, the consistency and magnitude of the changes seen are not emulated and this is likely due to differences in biology, lifestyle and experimental control. Finally, there is significant heterogeneity within the literature as to the efficacy of RWP interventions targeting human vascular health and function, and for this reason future research needs to address the scope of conditions for which RWP are beneficial and the dose and duration required for a given intervention and population. Overall, at present it is not possible to accurately predict the effects of RWP supplements due to the significant levels of heterogeneity between studies. Further research in RWP must focus on how to improve consistency and generalisability of findings through more effective control of confounding factors, such as medication status, diet composition and daily physical activity levels.

Author contributions Conceptualisation and study design were carried out by SW, SL, and CR. Literature searches and data analysis were carried out by SW. All authors contributed to the drafting and critical revision of the work. 
Funding SRW was supported by a BBSRC MIBTP Studentship. HMM was supported by an Arthritis Research UK Career Development Fellowship (19899).

\section{Compliance with ethical standards}

Conflict of interest HMM has received research funding from Pfizer. AP has received funding from Elysium Health. All other authors declare that they have no conflicts of interest.

Ethical approval All studies included in this review were screened for full ethical approval in accordance with the 1964 Declaration of Helsinki.

Open Access This article is licensed under a Creative Commons Attribution 4.0 International License, which permits use, sharing, adaptation, distribution and reproduction in any medium or format, as long as you give appropriate credit to the original author(s) and the source, provide a link to the Creative Commons licence, and indicate if changes were made. The images or other third party material in this article are included in the article's Creative Commons licence, unless indicated otherwise in a credit line to the material. If material is not included in the article's Creative Commons licence and your intended use is not permitted by statutory regulation or exceeds the permitted use, you will need to obtain permission directly from the copyright holder. To view a copy of this licence, visit http://creativecommons.org/licenses/by/4.0/.

\section{References}

1. Ferrieres J (2004) The French paradox: lessons for other countries. Heart 90:107-111. https://doi.org/10.1136/heart.90.1.107

2. Xia E, Deng G, Guo Y, Li H (2010) Biological activities of polyphenols from grapes 622-646. https://doi.org/10.3390/ ijms11020622.

3. Dell'Agli M, Buscialà A, Bosisio E (2004) Vascular effects of wine polyphenols. Cardiovasc Res 63:593-602. https://doi. org/10.1016/j.cardiores.2004.03.019

4. Bhatt SR, Lokhandwala MF, Banday AA (2011) Resveratrol prevents endothelial nitric oxide synthase uncoupling and attenuates development of hypertension in spontaneously hypertensive rats. Eur J Pharmacol 667:258-264. https://doi. org/10.1016/j.ejphar.2011.05.026

5. Idris Khodja N, Chataigneau T, Auger C, Schini-Kerth VB, Khodja NI, Chataigneau T et al (2012) Grape-derived polyphenols improve aging-related endothelial dysfunction in rat mesenteric artery: role of oxidative stress and the angiotensin system. PLoS ONE 7:e32039. https://doi.org/10.1371/journ al.pone. 0032039

6. Mozafari M, Nekooeian A, Panjeshahin M, Zare H (2015) The effects of resveratrol in rats with simultaneous type 2 diabetes and renal hypertension: a study of antihypertensive mechanisms. Iran J Med Sci 40:152-160

7. Robich MP, Osipov RM, Nezafat R, Feng J, Clements RT, Bianchi C et al (2010) Resveratrol improves myocardial perfusion in a swine model of hypercholesterolemia and chronic myocardial ischemia. Circulation 122:S142-S149. https://doi. org/10.1161/CIRCULATIONAHA.109.920132

8. Zou JG, Wang ZR, Huang YZ, Cao KJ, Wu JM (2003) Effect of red wine and wine polyphenol resveratrol on endothelial function in hypercholesterolemic rabbits. Int J Mol Med $11: 317-320$
9. Dolinsky VW, Rogan KJ, Sung MM, Zordoky BN, Haykowsky MJ, Young ME et al (2013) Both aerobic exercise and resveratrol supplementation attenuate doxorubicin-induced cardiac injury in mice. Am J Physiol Endocrinol Metab 305:E243-E253. https:// doi.org/10.1152/ajpendo.00044.2013

10. Ungvari Z, Bagi Z, Feher A, Recchia FA, Sonntag WE, Pearson $K$ et al (2010) Resveratrol confers endothelial protection via activation of the antioxidant transcription factor Nrf2. Am J Physiol Heart Circ Physiol 299:H18-24

11. Álvarez E, Rodiño-Janeiro BK, Jerez M, Ucieda-Somoza R, Núñez MJ, González-Juanatey JR (2012) Procyanidins from grape pomace are suitable inhibitors of human endothelial NADPH oxidase. J Cell Biochem 113:1386-1396. https://doi. org/10.1002/jcb.24011

12. Chen ML, Yi L, Jin X, Liang XY, Zhou Y, Zhang T et al (2013) Resveratrol attenuates vascular endothelial inflammation by inducing autophagy through the cAMP signaling pathway. Autophagy 9:2033-2045. https://doi.org/10.4161/auto.26336

13. Elíes J, Cuíñas A, García-Morales V, Orallo F, Campos-Toimil M (2011) Trans-resveratrol simultaneously increases cytoplasmic $\mathrm{Ca} 2+$ levels and nitric oxide release in human endothelial cells. Mol Nutr Food Res 55:1237-1248. https://doi.org/10.1002/ mnfr.201100240

14. Li S-H, Tian H-B, Zhao H-J, Chen L-H, Cui L-Q (2013) The acute effects of grape polyphenols supplementation on endothelial function in adults: meta-analyses of controlled trials. PLoS One;8. https://doi.org/10.1371/journal.pone.0069818

15. Zhang H, Liu SSS, Li L, Liu SSS, Liu SSS, Mi J et al (2016) The impact of grape seed extract treatment on blood pressure changes: A meta-analysis of 16 randomized controlled trials. Medicine (Baltimore) 95:e4247. https://doi.org/10.1097/ MD.0000000000004247

16. Barona J, Aristizabal JC, Blesso CN, Volek JS, Fernandez ML (2012) Grape polyphenols reduce blood pressure and increase flow-mediated vasodilation in men with metabolic syndrome. J Nutr 142:1626-1632. https://doi.org/10.3945/jn.112.162743

17. Timmers S, Konings E, Bilet L, Houtkooper H, Van De Weijer $\mathrm{T}$, Goossens GH et al (2011) Calorie restriction-like effects of 30 days of resveratrol supplementation on energy metabolism and metabolic profile in obese humans. Cell Metab 14:612-622. https://doi.org/10.1016/j.cmet.2011.10.002

18. Mellen PB, Daniel KR, Brosnihan KB, Hansen KJ, Herrington DM (2010) Effect of muscadine grape seed supplementation on vascular function in subjects with or at risk for cardiovascular disease: a randomized crossover trial. J Am Coll Nutr 29:469-475

19. Timmers S, de Ligt M, Phielix E, van de Weijer T, Hansen J, Moonen-Kornips E et al (2016) Resveratrol as add-on therapy in subjects with well-controlled type 2 diabetes: a randomized controlled trial. Diabetes Care 39:2211-2217. https://doi. org/10.2337/dc16-0499.

20. Croft KD (2016) Dietary polyphenols: antioxidants or not? Arch Biochem Biophys 595:120-124. https://doi.org/10.1016/j. abb.2015.11.014

21. Kulkarni SS, Cantó C (2015) The molecular targets of resveratrol. Biochim Biophys Acta Mol Basis Dis 1852:1114-1123. https://doi.org/10.1016/j.bbadis.2014.10.005

22. Schmitt CA, Heiss EH, Dirsch VM (2010) Effect of resveratrol on endothelial cell function: molecular mechanisms. BioFactors 36:342-349. https://doi.org/10.1002/biof.109

23. Leikert JF, Räthel TR, Wohlfart P, Cheynier V, Vollmar AM, Dirsch VM (2002) Red wine polyphenols enhance endothelial nitric oxide synthase expression and subsequent nitric oxide release from endothelial cells. Circulation 106:1614-1617. https ://doi.org/10.1161/01.CIR.0000034445.31543.43 
24. Cao X, Luo T, Luo X, Tang Z (2014) Resveratrol prevents AngIIinduced hypertension via AMPK activation and RhoA/ROCK suppression in mice. Hypertens Res 37:803-810. https://doi. org/10.1038/hr.2014.90.

25. Zhang H, Zhang J, Ungvari Z, Zhang C (2009) Resveratrol improves endothelial function: role of TNF $\alpha$ and vascular oxidative stress. Arterioscler Thromb Vasc Biol 29:1164-1171. https ://doi.org/10.1161/ATVBAHA.109.187146

26. Khodja NI, Chataigneau T, Auger C, Schini-Kerth VB, Idris Khodja N, Chataigneau T et al (2012) Grape-derived polyphenols improve aging-related endothelial dysfunction in rat mesenteric artery: role of oxidative stress and the angiotensin system. PLoS ONE 7:e32039-e32039

27. van Mierlo LAJ, Zock PL, van der Knaap HCM, Draijer R (2010) Grape polyphenols do not affect vascular function in healthy men. J Nutr 140:1769-1773. https://doi.org/10.3945/ jn. 110.125518

28. Yoshino J, Conte C, Fontana L, Mittendorfer B, Imai SI, Schechtman KB et al (2012) Resveratrol supplementation does not improve metabolic function in nonobese women with normal glucose tolerance. Cell Metab 16:658-664. https://doi.org/10.1016/j. cmet.2012.09.015

29. van der Made SM, Plat J, Mensink RP (2017) Trans-resveratrol supplementation and endothelial function during the fasting and postprandial phase: a randomized placebo-controlled trial in overweight and slightly obese participants. Nutrients 9:596. https://doi.org/10.3390/nu9060596

30. Botden IPG, Draijer R, Westerhof BE, Rutten JHW, Langendonk JG, Sijbrands EJG et al (2012) Red wine polyphenols do not lower peripheral or central blood pressure in high normal blood pressure and hypertension. Am J Hypertens 25:718-723. https ://doi.org/10.1038/ajh.2012.25

31. Draijer R, de Graaf Y, Slettenaar M, de Groot E, Wright CI (2015) Consumption of a polyphenol-rich grape-wine extract lowers ambulatory blood pressure in mildly hypertensive subjects. Nutrients 7:3138-3153. https://doi.org/10.3390/nu7053138

32. Bolca S, Van de Wiele T, Possemiers S (2013) Gut metabotypes govern health effects of dietary polyphenols. Curr Opin Biotechnol 24:220-225. https://doi.org/10.1016/j.copbio.2012.09.009

33. van Dorsten FA, Grun CH, van Velzen EJJ, Jacobs DM, Draijer R, van Duynhoven JPM (2010) The metabolic fate of red wine and grape juice polyphenols in humans assessed by metabolomics. Mol Nutr Food Res 54:897-908. https://doi.org/10.1002/ mnfr.200900212

34. van Duynhoven J, Vaughan EE, Jacobs DM, Kempermanvan VelzenGross REJJG et al (2011) Metabolic fate of polyphenols in the human superorganism. Proc Natl Acad Sci 108:4531-4538. https://doi.org/10.1073/pnas.1000098107

35. Hugenholtz F, de Vos WM (2018) Mouse models for human intestinal microbiota research: a critical evaluation. Cell Mol Life Sci 75:149-160. https://doi.org/10.1007/s00018-017-2693-8

36. Reagen-Shaw S, Nihal M, Ahmad N (2007) Dose translation from animal to human studies revisited. FASEB J 22:659-661. https://doi.org/10.1096/fj.07-9574LSF

37. Sofi F, Abbate R, Gensini GF, Casini A (2010) Accruing evidence on benefits of adherence to the Mediterranean diet on health: an updated systematic review and meta-analysis. Am J Clin Nutr 1(2):1189-1196. https://doi.org/10.3945/ajcn.2010.29673 INTRODUCTION

38. Allen K, Morey MC (2010) Improving patient treatment adherence. Clin Guide. https://doi.org/10.1007/978-1-4419-5866-2

39. Zhang H, Liu S, Li L, Liu S, Liu S, Mi J et al (2016) The impact of grape seed extract treatment on blood pressure changes. A meta-analysis of 16 randomized controlled trials. Medicine (Baltimore) 95. https://doi.org/10.1097/MD.0000000000004247
40. Liu Y, Ma W, Zhang P, He S, Huang D (2015) Effect of resveratrol on blood pressure: A meta-analysis of randomized controlled trials. Clin Nutr 34:27-34. https://doi.org/10.1016/j. clnu.2014.03.009

41. Moher D, Liberati A, Tetzlaff J, Altman DG, Altman D, Antes $G$ et al (2009) Preferred reporting items for systematic reviews and meta-analyses: the PRISMA statement. PLoS Med 6. https ://doi.org/10.1371/journal.pmed.1000097

42. Moher D, Shamseer L, Clarke M, Ghersi D, Liberati A, Petticrew $M$ et al (2015) Preferred reporting items for systematic review and meta-analysis protocols (PRISMA-P) 2015 statement. Syst Rev 4:1-9. https://doi.org/10.1186/2046-4053-4-1

43. Needleman IG (2002) A guide to systematic reviews. J Clin Periodontol 29:6-9. https://doi.org/10.1034/j.1600-051X.29.s3.15.x

44. Ouzzani M, Hammady H, Fedorowicz Z, Elmagarmid A (2016) Rayyan - a web and mobile app for systematic reviews. Syst Rev 5. https://doi.org/10.1186/s13643-016-0384-4

45. Cordova AC, Sumpio BE (2009) Polyphenols are medicine: Is it time to prescribe red wine for our patients? Int J Angiol 18:111117. https://doi.org/10.1055/s-0031-1278336

46. Shamseer L, Moher D, Clarke M, Ghersi D, Liberati A, Petticrew $M$ et al (2015) Preferred reporting items for systematic review and meta-analysis protocols (prisma-p) 2015: elaboration and explanation. BMJ 349:1-25. https://doi.org/10.1136/bmj.g7647

47. Higgins JPT, Altman DG, Gøtzsche PC, Jüni P, Moher D, Oxman AD et al (2011) The Cochrane Collaboration's tool for assessing risk of bias in randomised trials. BMJ 343:1-9. https://doi. org/10.1136/bmj.d5928

48. Higgins J, Green S (2011) Cochrane handbook for systematic reviews of interventions version 5.1.0 (updated March 2011). Cochrane Collab 2011

49. Wan X, Wang W, Liu J, Tong T (2014) Estimating the sample mean and standard deviation from the sample size, median, range and/or interquartile range. BMC Med Res Methodol 14:1-13. https://doi.org/10.1186/1471-2288-14-135

50. Higgins JPT, Thompson SG, Deeks JJ, Altman DG (2003) Measuring inconsistency in meta-analyses. BMJ Br Med J 327:557560. https://doi.org/10.1136/bmj.327.7414.557

51. Viechtbauer W (2007) Accounting for heterogeneity via random-effects models and moderator analyses in metaanalysis. Z Psychol/J Psychol 215:104-121. https://doi. org/10.1027/0044-3409.215.2.104

52. Viechtbauer W, Cheung MW-L (2010) Outlier and influence diagnostics for meta-analysis. Res Synth Methods 1:112-125. https://doi.org/10.1002/jrsm.11

53. Team RC (2017) R: a language and environment for statistical computing

54. Viechtbauer W (2010) Conducting meta-analyses in $\mathrm{R}$ with the metafor package. J Stat Softw 36:1-48. https://doi.org/10.1103/ PhysRevB.91.121108

55. Dal-Ros S, Bronner C, Auger C, Schini-Kerth V (2012) Red wine polyphenols improve an established aging-related endothelial dysfunction in the mesenteric artery of middle-aged rats: Role of oxidative stress. Biochem Biophys Res Commun 419:381-387. https://doi.org/10.1016/j.bbrc.2012.02.031

56. Gocmez SS, Scarpace PJ, Whidden MA, Erdos B, Kirichenko N, Sakarya Y et al (2016) Age Impaired endothelium-dependent vasodilation is improved by resveratrol in rat mesenteric arteries. J Exerc Nutr Biochem 20:41-48

57. Franco JG, Lisboa PC, Lima NS, Amaral TAS, Peixoto-Silva N, Resende AC et al (2013) Resveratrol attenuates oxidative stress and prevents steatosis and hypertension in obese rats programmed by early weaning. J Nutr Biochem 24:960-966. https ://doi.org/10.1016/j.jnutbio.2012.06.019

58. Jang H-H, Park SK, Choi G-Y, Park J-H, Lee T-H, Jung H-N et al (2015) Anti-hypertensive effect of grape seed extract in 
male spontaneously hypertensive rats. Food Sci Biotechnol 24:2229-2233

59. Jendekova L, Kojsova S, Andriantsitohaina R, Pechanova O (2006) The time-dependent effect of Provinols(TM) on brain NO synthase activity in L-NAME-induced hypertension. Physiol Res 55:S31-S37

60. Jiménez R, López-Sepúlveda R, Kadmiri MM, Romero M, Vera RR, Sánchez M et al (2007) Polyphenols restore endothelial function in DOCA-salt hypertension: Role of endothelin-1 and NADPH oxidase. Free Radic Biol Med 43:462-473. https://doi. org/10.1016/j.freeradbiomed.2007.05.007

61. Kavas GOGÖ, Ayral PA, Elhan AH (2013) The effects of resveratrol on oxidant/antioxidant systems and their cofactors in rats. Adv Clin Exp Med 22:151-155

62. Idris-Khodja N, Di Marco P, Farhat M, Geny B, Schini-Kerth VB (2013) Grape-derived polyphenols prevent doxorubicin-induced blunted EDH-mediated relaxations in the rat mesenteric artery: Role of ROS and angiotensin II. Evidence-Based Complement Altern Med 2013:516017. https://doi.org/10.1155/2013/516017

63. Kosuru R, Singh S (2017) Pterostilbene ameliorates insulin sensitivity, glycemic control and oxidative stress in fructose-fed diabetic rats. LIFE Sci 182:112-121. https://doi.org/10.1016/j. lfs.2017.06.015

64. Louis XL, Thandapilly SJ, MohanKumar SK, Yu L, Taylor CG, Zahradka P et al (2012) Treatment with low-dose resveratrol reverses cardiac impairment in obese prone but not in obese resistant rats. J Nutr Biochem 23:1163-1169. https://doi. org/10.1016/j.jnutbio.2011.06.010

65. Akar F, Uludag O, Aydin A, Aytekin YA, Elbeg S, Tuzcu M et al (2012) High-fructose corn syrup causes vascular dysfunction associated with metabolic disturbance in rats: Protective effect of resveratrol. Food Chem Toxicol 50:2135-2141. https://doi. org/10.1016/j.fct.2012.03.061

66. Majumdar AS, Joshi PA, Giri PR (2013) Resveratrol attenuated smokeless tobacco-induced vascular and metabolic complications in ovariectomized rats. Menopause 20:869-876

67. Miatello R, Vazquez M, Renna N, Cruzado M, Zumino AP, Risler N (2005) Chronic administration of resveratrol prevents biochemical cardiovascular changes in fructose-fed rats. Am J Hypertens 18:864-870. https://doi.org/10.1016/j.amjhy per.2004.12.012

68. Mizutani K, Ikeda K, Kawai Y, Yamori Y (2000) Resveratrol attenuates ovariectomy-induced hypertension and bone loss in stroke-prone spontaneously hypertensive rats. J Nutr Sci Vitaminol (Tokyo) 46:78-83

69. Mizutani K, Ikeda K, Kawai Y, Yamori Y (2001) Protective effect of resveratrol on oxidative damage in male and female strokeprone spontaneously hypertensive rats. Clin Exp Pharmacol Physiol 28:55-59

70. Moraloglu O, Engin-Ustun Y, Tonguç E, Var T, Tapisiz ÖL, Ergün $\mathrm{H}$ et al (2012) The effect of resveratrol on blood pressure in a rat model of preeclampsia. J Matern Neonatal Med 25:845-848. https://doi.org/10.3109/14767058.2011.599081

71. Mozafari M, Nekooeian AA, Panjeshahin MR (2016) The antihyperlipidemic effects of resveratrol in rats with simultaneous type II diabetes and renovascular hypertension. Int Cardiovasc Res J 10:165-171

72. Ozan G, Bircan FS, Pasaoglu OT, Topal T, Turkozkan N (2017) Evaluation of effects of resveratrol on brain nitric oxide and energy metabolism in metabolic syndrome model. J Clin Anal Med 8:350-354

73. Cheng P-W, Lee H-C, Lu P-J, Chen H-H, Lai C-C, Sun G-C et al (2016) Resveratrol inhibition of Rac1-derived reactive oxygen species by AMPK decreases blood pressure in a fructose-induced rat model of hypertension. Sci Rep 6:25342. https://doi. org/10.1038/srep25342

74. Phyu HE, Irwin JC, Vella RK, Fenning AS (2016) Resveratrol shows neuronal and vascular-protective effects in older, obese, streptozotocin-induced diabetic rats. Br J Nutr 115:1911-1918. https://doi.org/10.1017/S0007114516001069

75. Puzserova A, Csizmadiova Z, Andriantsitohaina R, Bernatova I (2006) Vascular effects of red wine polyphenols in chronic stressexposed Wistar-Kyoto rats. Physiol Res 55:S39-47

76. Aribal-Kocatuerk P, Kavas GO, Bueyuekkagnici DI (2007) Pretreatment effect of resveratrol on streptozotocin-induced diabetes in rats. Biol Trace Elem Res 118:244-249. https://doi. org/10.1007/s12011-007-0031-y

77. Rezzani R, Tengattini S, Bonomini F, Filippini F, Pechánová $\mathrm{O}$, Bianchi R et al (2009) Red wine polyphenols prevent cyclosporine-induced nephrotoxicity at the level of the intrinsic apoptotic pathway. Physiol Res 58:511-519

78. Rivera L, Morón R, Zarzuelo A, Galisteo M (2009) Long-term resveratrol administration reduces metabolic disturbances and lowers blood pressure in obese Zucker rats. Biochem Pharmacol 77:1053-1063. https://doi.org/10.1016/j.bcp.2008.11.027

79. Rush JWE, Quadrilatero J, Levy AS, Ford RJ et al (2007) Chronic resveratrol enhances endothelium-dependent relaxation but does not alter eNOS levels in aorta of spontaneously hypertensive rats. Exp Biol Med 232:814-822. https://doi.org/10.3181/00379 727-181-42261

80. Soylemez S, Sepici A, Akar F (2009) Resveratrol supplementation gender independently improves endothelial reactivity and suppresses superoxide production in healthy rats. Cardiovasc Drugs Ther 23:449-458. https://doi.org/10.1007/s1055 7-009-6198-z

81. Thandapilly SJ, Wojciechowski P, Behbahani J, Louis XL, Yu L, Juric D et al (2010) Resveratrol prevents the development of pathological cardiac hypertrophy and contractile dysfunction in the SHR without lowering blood pressure. Am J Hypertens 23:192-196

82. Aubin M, Lajoie C, Cle R, Gosselin H, Calderone A, Perrault LP (2008) Female rats fed a high-fat diet were associated with vascular dysfunction and cardiac fibrosis in the absence of overt obesity and hyperlipidemia : therapeutic potential of resveratrol. Pharmacology 325:961-968. https://doi.org/10.1124/ jpet.107.135061.artery

83. Bernatova I, Pechanova O, Babal P, Kysela S, Stvrtina S, Andriantsitohaina R (2002) Wine polyphenols improve cardiovascular remodeling and vascular function in NO-deficient hypertension. Am J Physiol Circ Physiol 282:H942-H948

84. Biala A, Tauriainen E, Siltanen A, Shi J, Merasto S, Louhelainen $M$ et al (2010) Resveratrol induces mitochondrial biogenesis and ameliorates Ang II-induced cardiac remodeling in transgenic rats harboring human renin and angiotensinogen genes. Blood Press 19:196-205

85. Cheng PW, Ho WY, Su YT, Lu PJ, Chen BZ, Cheng WH et al (2014) Resveratrol decreases fructose-induced oxidative stress, mediated by NADPH oxidase via an AMPK-dependent mechanism. Br J Pharmacol 171:2739-2750. https://doi.org/10.1111/ bph. 12648

86. Lee DI, Acosta C, Anderson CM, Anderson HD (2017) Peripheral and cerebral resistance arteries in the spontaneously hypertensive heart failure rat: effects of stilbenoid polyphenols. Molecules 22. https://doi.org/10.3390/molecules22030380

87. da Luz PL, Tanaka L, Brum PC, Martins Dourado PM, Favarato D, Krieger JE et al (2012) Red wine and equivalent oral pharmacological doses of resveratrol delay vascular aging but do not extend life span in rats. Atherosclerosis 224:136-142 
88. Cheserek MJ, Wu G, Li LL, Li LL, Karangwa E, Shi Y et al (2016) Cardioprotective effects of lipoic acid, quercetin and resveratrol on oxidative stress related to thyroid hormone alterations in long-term obesity. J Nutr Biochem 33:36-44. https://doi. org/10.1016/j.jnutbio.2016.02.008

89. Dolinsky VW, Chakrabarti S, Pereira TJ, Oka T, Levasseur J, Beker D et al (2013) Resveratrol prevents hypertension and cardiac hypertrophy in hypertensive rats and mice. Biochim Biophys Acta-Mol Basis Dis 1832:1723-1733

90. Hort MA, Schuldt EZ, Bet AC, DalBo S, Siqueira JM, Ianssen $C$ et al (2012) Anti-atherogenic effects of a phenol-rich fraction from Brazilian red wine (Vitis labrusca L.) in hypercholesterolemic low-density lipoprotein receptor knockout mice. J Med Food 15:936-944. https://doi.org/10.1089/jmf.2011.0333

91. Inanaga $\mathrm{K}$, Ichiki $\mathrm{T}$, Matsuura $\mathrm{H}$, Miyazaki R, Hashimoto $\mathrm{T}$, Takeda K et al (2009) Resveratrol attenuates angiotensin IIinduced interleukin- 6 expression and perivascular fibrosis. Hypertens Res 32:466-471

92. Gendron M-E, Thorin-Trescases N, Mamarbachi AM, Villeneuve L, Theoret J-F, Mehri Y et al (2012) Time-dependent beneficial effect of chronic polypenol treatment with catechin on endothelial dysfunction in aging mice. Dose-Response 10:108-119

93. Toth P, Tarantini S, Tucsek Z, Ashpole NM, Sosnowska D, Gautam $T$ et al (2014) Resveratrol treatment rescues neurovascular coupling in aged mice: role of improved cerebromicrovascular endothelial function and downregulation of NADPH oxidase. Am J Physiol Heart Circ Physiol 306:H299-308

94. Toth P, Tarantini S, Springo Z, Tucsek Z, Gautam T, Giles CB et al (2015) Aging exacerbates hypertension-induced cerebral microhemorrhages in mice: role of resveratrol treatment in vasoprotection. Aging Cell 14:400-408. https://doi.org/10.1111/ acel.12315

95. Wang G, Song X, Zhao L, Li Z, Liu B (2018) Resveratrol prevents diabetic cardiomyopathy by increasing Nrf2 expression and transcriptional activity. Biomed Res Int. https://doi. org/10.1155/2018/2150218

96. Akar F, Pektas MB, Tufan C, Soylemez S, Sepici A, Ulus AT et al (2011) Resveratrol shows vasoprotective effect reducing oxidative stress without affecting metabolic disturbances in insulin-dependent diabetes of rabbits. Cardiovasc Drugs Ther 25:119-131. https://doi.org/10.1007/s10557-010-6255-7

97. Reagan-Shaw S, Nihal M, Ahmad N (2007) Dose translation from animal to human studies revisited. FASEB J 22:659-661. https://doi.org/10.1096/fj.07-9574LSF

98. Nair A, Jacob S (2016) A simple practice guide for dose conversion between animals and human. J Basic Clin Pharm 7:27. https ://doi.org/10.4103/0976-0105.177703

99. Clifton PM. (2004) Effect of grape seed extract and quercetin on cardiovascular and endothelial parameters in high-risk subjects. J Biomed Biotechnol 272-278

100. Vaisman N, Niv E (2015) Daily consumption of red grape cell powder in a dietary dose improves cardiovascular parameters: a double blind, placebo-controlled, randomized study. Int J Food Sci Nutr 66:342-349. https://doi.org/10.3109/09637 486.2014.1000840

101. Wightman EL, Reay JL, Haskell CF, Williamson G, Dew TP, Kennedy DO (2014) Effects of resveratrol alone or in combination with piperine on cerebral blood flow parameters and cognitive performance in human subjects: A randomised, doubleblind, placebo-controlled, cross-over investigation. Br J Nutr 112:203-213. https://doi.org/10.1017/S0007114514000737

102. Wong RHX, Howe PRC, Buckley JD, Coates AM, Kunz I, Berry NM (2011) Acute resveratrol supplementation improves flowmediated dilatation in overweight/obese individuals with mildly elevated blood pressure. Nutr Metab Cardiovasc Dis 21:851-856. https://doi.org/10.1016/j.numecd.2010.03.003
103. Wong RHX, Berry NM, Coates AM, Buckley JD, Bryan J, Kunz I et al (2013) Chronic resveratrol consumption improves brachial flow-mediated dilatation in healthy obese adults. J Hypertens 31:1819-1827

104. Xue M, Weickert MO, Qureshi S, Kandala N-B, Anwar A, Waldron $\mathrm{M}$ et al (2016) Improved glycemic control and vascular function in overweight and obese subjects by glyoxalase 1 inducer formulation. Diabetes 65:2282-2294. https://doi. org/10.2337/db16-0153

105. Bo S, Ciccone G, Castiglione A, Gambino R, De Michieli F, Villois P et al (2013) Anti-inflammatory and antioxidant effects of resveratrol in healthy smokers a randomized, double-blind, placebo-controlled, cross-over trial. Curr Med Chem 20:13231331. https://doi.org/10.2174/0929867311320100009

106. Marques BCAA, Trindade M, Aquino JCF, Cunha AR, Gismondi RO, Neves MF et al (2018) Beneficial effects of acute transresveratrol supplementation in treated hypertensive patients with endothelial dysfunction. Clin Exp Hypertens 40:218-223

107. Kennedy DO, Wightman EL, Reay JL, Lietz G, Okello EJ, Wilde A et al (2010) Effects of resveratrol on cerebral blood flow variables and cognitive performance in humans : a double-blind, placebo-controlled, crossover. Am J Clin Nutr 91:1590-1597. https://doi.org/10.3945/ajen.2009.28641

108. Khodabandehloo H, Seyyedebrahimi SS, Esfahani EN, Razi F, Meshkani R (2018) Resveratrol supplementation decreases blood glucose without changing the circulating CD14+CD16+ monocytes and inflammatory cytokines in patients with type 2 diabetes: a randomized, double-blind, placebo-controlled study. Nutr Res 54:40-51. https://doi.org/10.1016/j.nutres.2018.03.015

109. Kjaer TN, Ornstrup MJ, Poulsen MM, Stodkilde-Jorgensen H, Jessen N, Jorgensen JOL et al (2017) No beneficial effects of resveratrol on the metabolic syndrome: a randomized placebocontrolled clinical trial. J Clin Endocrinol Metab 102:1642-1651

110. Lekakis J, Rallidis LS, Andreadou I, Vamvakou G, Kazantzoglou G, Magiatis P et al (2005) Polyphenolic compounds from red grapes acutely improve endothelial function in patients with coronary heart disease. Eur J Cardiovasc Prev Rehabil 12:596-600. https://doi.org/10.1097/00149831-200512000-00013

111. Magyar K, Halmosi R, Palfi A, Feher G, Czopf L, Fulop A et al (2012) Cardioprotection by resveratrol: a human clinical trial in patients with stable coronary artery disease. Clin Hemorheol Microcirc 50:179-187. https://doi.org/10.3233/CH-2011-1424

112. Movahed A, Nabipour I, Louis XL, Thandapilly SJ, Yu L, Kalantarhormozi M et al (2013) Antihyperglycemic effects of short term resveratrol supplementation in type 2 diabetic patients. Evid Based Complement Altern Med 2013:851267. https://doi. org/10.1155/2013/851267

113. Pérez-Jiménez J, Serrano J, Tabernero M, Arranz S, Díaz-Rubio ME, García-Diz L et al (2008) Effects of grape antioxidant dietary fiber in cardiovascular disease risk factors. Nutrition 24:646-653. https://doi.org/10.1016/j.nut.2008.03.012

114. Ras RT, Zock PL, Zebregs YEMP, Johnston NR, Webb DJ, Draijer R (2013) Effect of polyphenol-rich grape seed extract on ambulatory blood pressure in subjects with pre- and stage I hypertension. Br J Nutr 110:2234-2241

115. Riche DM, Riche KD, Blackshear CT, McEwen CL, Sherman JJ, Wofford MR et al (2014) Pterostilbene on metabolic parameters: a randomized, double-blind, and placebo-controlled trial. Evidence-Based Complement Altern Med 2014:459165. https:// doi.org/10.1155/2014/459165

116. Sano A, Uchida R, Saito M, Shioya N, Komori Y, Tho Y et al (2007) Beneficial effects of grape seed extract on malondialdehyde-modified LDL. J Nutr Sci Vitaminol (Tokyo) 53:174-182. https://doi.org/10.3177/jnsv.53.174 
117. Bhatt JK, Thomas S, Nanjan MJ. (2012) Resveratrol supplementation improves glycemic control in type 2 diabetes mellitus. Nutr Res 32:537-541. https://doi.org/10.1016/j.nutres.2012.06.003

118. Seyyedebrahimi S, Khodabandehloo H, Nasli Esfahani E, Meshkani R (2018) The effects of resveratrol on markers of oxidative stress in patients with type 2 diabetes: a randomized, doubleblind, placebo-controlled clinical trial. Acta Diabetol 55:341353. https://doi.org/10.1007/s00592-017-1098-3

119. Sivaprakasapillai B, Edirisinghe I, Randolph J, Steinberg F, Kappagoda T (2009) Effect of grape seed extract on blood pressure in subjects with the metabolic syndrome. Metab Exp 58:1743-1746

120. Terauchi M, Horiguchi N, Kajiyama A, Akiyoshi M, Owa Y, Kato K et al (2014) Effects of grape seed proanthocyanidin extract on menopausal symptoms, body composition, and cardiovascular parameters in middle-aged women: a randomized, double-blind, placebo-controlled pilot study. Menopause 21:990996. https://doi.org/10.1097/GME.0000000000000200

121. Tome-Carneiro J, Larrosa M, Yanez-Gascon MJ, Davalos A, Gil-Zamorano J, Gonzalvez M et al (2013) One-year supplementation with a grape extract containing resveratrol modulates inflammatory-related microRNAs and cytokines expression in peripheral blood mononuclear cells of type 2 diabetes and hypertensive patients with coronary artery disease. Pharmacol Res 72:69-82. https://doi.org/10.1016/j. phrs.2013.03.011

122. Wong RHX, Nealon RS, Scholey A, Howe PRC (2016) Low dose resveratrol improves cerebrovascular function in type 2 diabetes mellitus. Nutr Metab Cardiovasc Dis 26:393-399. https://doi. org/10.1016/j.numecd.2016.03.003

123. Wong RHX, Raederstorff D, Howe PRC (2016) Acute resveratrol consumption improves neurovascular coupling capacity in adults with type 2 diabetes mellitus. Nutrients $8: 425$. https://doi. org/10.3390/nu8070425

124. Bo S, Ponzo V, Ciccone G, Evangelista A, Saba F, Goitre I et al (2016) Six months of resveratrol supplementation has no measurable effect in type 2 diabetic patients. A randomized, double blind, placebo-controlled trial. Pharmacol Res 111:896-905. https://doi.org/10.1016/j.phrs.2016.08.010

125. Evans HM, Howe PRC, Wong RHX (2017) Effects of resveratrol on cognitive performance, mood and cerebrovascular function in post-menopausal women; a 14-week randomised placebo-controlled intervention trial. Nutrients 9:27. https://doi.org/10.3390/ nu9010027

126. Faghihzadeh F, Adibi P, Hekmatdoost A (2015) The effects of resveratrol supplementation on cardiovascular risk factors in patients with non-alcoholic fatty liver disease: a randomised, double-blind, placebo-controlled study. Br J Nutr 114:796-803. https://doi.org/10.1017/S0007114515002433

127. Fodor K, Tit DM, Pasca B, Bustea C, Uivarosan D, Endres L et al (2018) Long-term resveratrol supplementation as a secondary prophylaxis for stroke. Oxid Med Cell Longev 2018:4147320. https://doi.org/10.1155/2018/4147320

128. Fujitaka K, Otani H, Jo F, Jo H, Nomura E, Iwasaki M et al (2011) Modified resveratrol Longevinex improves endothelial function in adults with metabolic syndrome receiving standard treatment. Nutr Res 31:842-847. https://doi.org/10.1016/j.nutre s.2011.09.028

129. Heeboll S, Kreuzfeldt M, Hamilton-Dutoit S, Kjaer Poulsen M, Stodkilde-Jorgensen H, Moller HJ et al (2016) Placebo-controlled, randomised clinical trial: High-dose resveratrol treatment for non-alcoholic fatty liver disease. Scand J Gastroenterol 51:456-463. https://doi.org/10.3109/00365521.2015.1107620

130. Imamura $H$, Yamaguchi $T$, Nagayama D, Saiki A, Shirai K, Tatsuno I et al (2017) Resveratrol ameliorates arterial stiffness assessed by cardio-ankle vascular index in patients with type 2 diabetes mellitus. Int Heart J 58:577-583. https://doi. org/10.1536/ihj.16-373

131. Wightman EL, Haskell-Ramsay CF, Reay JL, Williamson G, Dew T, Zhang W et al (2015) The effects of chronic trans-resveratrol supplementation on aspects of cognitive function, mood, sleep, health and cerebral blood flow in healthy, young humans. Br J Nutr 114:1427-1437

132. Wong RHX, Howe PRC, Buckley JD, Coates AM, Kunz I, Berry NM (2011) Acute resveratrol supplementation improves flowmediated dilatation in overweight/obese individuals with mildly elevated blood pressure. Nutr Metab Cardiovasc Dis 21:851-856

133. Van Der Made SM, Plat J, Mensink RP (2015) Resveratrol does not influence metabolic risk markers related to cardiovascular health in overweight and slightly obese subjects: A randomized, placebo-controlled crossover trial. PLoS ONE 10:1-13. https:// doi.org/10.1371/journal.pone.0118393

134. Riche DM, Riche KD, Blackshear CT, McEwen CL, Sherman JJ, Wofford MR et al (2014) Pterostilbene on metabolic parameters: a randomized, double-blind, and placebo-controlled trial. Evidence-Based Complement Altern Med. https://doi. org/10.1155/2014/459165

135. Khodabandehloo H, Seyyedebrahimi S, Esfahani EN, Razi F (2018) Resveratrol supplementation decreases blood glucose without changing the circulating CD14+CD16+ monocytes and inflammatory cytokines in patients with type 2 diabetes: a randomized, double-blind, placebo-controlled study. Nutr Res $54: 40-51$

136. Li S-H, Zhao P, Tian H-B, Chen L-H, Cui L-Q (2015) Effect of grape polyphenols on blood pressure: a meta-analysis of randomized controlled trials. PLoS One 10. https://doi.org/10.1371/ journal.pone. 0137665

137. Strandberg TE, Pitkala K (2003) What is the most important component of blood pressure : systolic, diastolic or pulse pressure? Hypertension 12:293-297. https://doi.org/10.1097/01. mnh.0000069868.94246.ef

138. Haider A, Larson MG, Franklin S, Levy D (2003) Systolic blood pressure, diastolic blood pressure, and pulse pressure as predictors of risk for congestive heart failure in the Framingham Heart Study. Ann Intern Med 138:10. https://doi.org/10.7326/00034819-138-1-200301070-00006

139. Egan BM, Stevens-Fabry S (2015) Prehypertension-prevalence, health risks, and management strategies. Nat Rev Cardiol 12:289-300. https://doi.org/10.1038/nrcardio.2015.17

140. Briasoulis A, Agarwal V, Valachis A, Messerli FH (2013) Antihypertensive effects of statins: a meta-analysis of prospective controlled studies. J Clin Hypertens 15:310-320. https://doi. org/10.1111/jch.12081

141. Kernan WN, Viscoli CM, Makuch RW, Brass LM, Horwitz RI (1999) Stratified randomization for clinical trials. J Clin Epidemiol 52:19-26. https://doi.org/10.1016/S0895-4356(98)00138-3

142. Carrizzo A, Puca A, Damato A, Marino M, Franco E, Pompeo F et al (2013) Resveratrol improves vascular function in patients with hypertension and dyslipidemia by modulating NO metabolism. Hypertension 62:359-366. https://doi.org/10.1161/HYPER TENSIONAHA.111.01009

143. Gocmez SS, Scarpace PJ, Whidden MA, Erdos B, Kirichenko N, Sakarya Y et al (2016) Age Impaired endothelium-dependent vasodilation is improved by resveratrol in rat mesenteric arteries. J Exerc Nutr Biochem 20:41-48. https://doi.org/10.20463/ jenb.2016.03.20.1.2

144. Kosuru R, Kandula V, Rai U, Prakash S, Xia Z, Singh S (2018) Pterostilbene decreases cardiac oxidative stress and inflammation via activation of AMPK/Nrf2/HO-1 pathway in fructose-fed diabetic rats. Cardiovasc Drugs Ther 32:147-163

145. Behbahani J, Thandapilly SJ, Louis XL, Huang Y, Shao Z, Kopilas MA et al (2010) Resveratrol and small artery compliance and 
remodeling in the spontaneously hypertensive rat. Am J Hypertens 23:1273-1278. https://doi.org/10.1038/ajh.2010.161

146. Gordish KL, Beierwaltes WH (2016) Chronic resveratrol reverses a mild angiotensin II-induced pressor effect in a rat model. Integr Blood Press Control 9:23-31

147. Inanaga $\mathrm{K}$, Ichiki $\mathrm{T}$, Matsuura $\mathrm{H}$, Miyazaki R, Hashimoto $\mathrm{T}$, Takeda K et al (2009) Resveratrol attenuates angiotensin IIinduced interleukin-6 expression and perivascular fibrosis. Hypertens Res 32:466-71. https://doi.org/10.1038/hr.2009.47

148. Mizutani K, Ikeda K, Kawai Y, Yamori Y, Loss B et al (2000) Resveratrol attenuates ovariectomy-induced hypertension and bone loss in stroke-prone spontaneously hypertensive rats. J Nutr Sci Vitaminol (Tokyo) 46:78-83. https://doi.org/10.3177/ jnsv.46.78

149. Ozan G, Bircan FS, Pasaoglu OT, Topal T, Turkozkan N, Medicine V et al (2017) Evaluation of effects of resveratrol on brain nitric oxide and energy metabolism in metabolic syndrome model. J Clin Anal Med 8:350-354. https://doi.org/10.4328/ JCAM.5074

150. Phyu HE, Irwin JC, Vella RK, Fenning AS (2016) Resveratrol shows neuronal and vascular-protective effects in older, obese, streptozotocin-induced diabetic rats. Br J Nutr 115:1911-1918

151. Hackam DG, Redelmeier DA (2006) Translation of research evidence from animals to humans. JAMA 296:1731-1732

152. Aribal-Kocatuerk P, Kavas GÖ, Coban U, Elhan AH (2009) How does resveratrol change some metabolic and circulatory parameters? A preliminary study*. Adv Clin Exp Med 18:323-328

153. Kapetanovic IM, Muzzio M, Huang Z, Thompson TN, McCormick DL (2011) Pharmacokinetics, oral bioavailability, and metabolic profile of resveratrol and its dimethylether analog, pterostilbene, in rats. Cancer Chemother Pharmacol 68:593-601. https://doi.org/10.1007/s00280-010-1525-4

154. van Dorsten FA, Grün CH, van Velzen EJJ, Jacobs DM, Draijer R, van Duynhoven JPM (2010) The metabolic fate of red wine and grape juice polyphenols in humans assessed by metabolomics. Mol Nutr Food Res 54:897-908. https://doi.org/10.1002/ mnfr.200900212
155. Ottaviani JI, Borges G, Momma TY, Spencer JPE, Keen CL, Crozier A et al (2016) The metabolome of [2-14C](-)-epicatechin in humans: Implications for the assessment of efficacy, safety, and mechanisms of action of polyphenolic bioactives. Sci Rep 6:1-10. https://doi.org/10.1038/srep29034

156. Wang P, Sang S (2018) Metabolism and pharmacokinetics of resveratrol and pterostilbene. BioFactors 44:16-25. https://doi. org/10.1002/biof.1410

157. Shanks N, Greek R, Greek J (2009) Are animal models predictive for humans? Philos Ethics Hum Med 4:1-20. https://doi. org/10.1186/1747-5341-4-2

158. Avogaro A, De Kreutzenberg SV (2005) Mechanisms of endothelial dysfunction in obesity. Clin Chim Acta 360:9-26. https://doi. org/10.1016/j.ccen.2005.04.020

159. De Vriese A, Verbeuren T, de Voorde J, Lamiere N, Vanhoutte $\mathrm{P}$ (2000) Endothelial dysfunction in diabetes. Br J Pharmacol 130:963-974

160. Virdis A (2016) Endothelial dysfunction in obesity: role of inflammation. High Blood Press Cardiovasc Prev 23:83-85. https ://doi.org/10.1007/s40292-016-0133-8

161. Walle T (2011) Bioavailability of resveratrol. Ann N Y Acad Sci 1215:9-15. https://doi.org/10.1111/j.1749-6632.2010.05842.x

162. Tsai HY, Ho CT, Chen YK (2017) Biological actions and molecular effects of resveratrol, pterostilbene, and 3'-hydroxypterostilbene. J Food Drug Anal 25:134-147. https://doi.org/10.1016/j. jfda.2016.07.004

163. Gliemann L, Schmidt JF, Olesen J, Bienso RS, Peronard SL, Grandjean SU et al (2013) Resveratrol blunts the positive effects of exercise training on cardiovascular health in aged men. J Physiol 591:5047-5059

164. Pedersen BK, Saltin B (2015) Exercise as medicine-evidence for prescribing exercise as therapy in 26 different chronic diseases. Scand J Med Sci Sport 25:1-72. https://doi.org/10.1111/ sms. 12581 